NATIONAL LABORATORY

\title{
Evidence-Based Background Material Underlying Guidance for Federal Agencies in Implementing Strategic Sustainability Performance Plans
}

\author{
Implementing Sustainability: \\ The Institutional-Behavioral Dimension
}

Elizabeth L. Malone

Tom Sanquist Amy K. Wolfe

Rick Diamond

Christopher Payne Jerry Dion

January 2011

(Updated June 2013)

Federal Energy Management Program

U.S. Department of Energy 


\section{DOCUMENT AVAILABILITY}

Reports produced after January 1, 1996, are generally available free via the U.S. Department of Energy (DOE) Information Bridge.

Web site http://www.osti.gov/bridge

Reports produced before January 1, 1996, may be purchased by members of the public from the following source.

National Technical Information Service

5285 Port Royal Road

Springfield, VA 22161

Telephone 703-605-6000 (1-800-553-6847)

TDD 703-487-4639

Fax 703-605-6900

E-mailinfo@ntis.gov

Web site http://www.ntis.gov/support/ordernowabout.htm

Reports are available to DOE employees, DOE contractors, Energy Technology Data Exchange (ETDE) representatives, and International Nuclear Information System (INIS) representatives from the following source.

Office of Scientific and Technical Information

P.O. Box 62

Oak Ridge, TN 37831

Telephone 865-576-8401

Fax 865-576-5728

E-mail reports@osti.gov

Web site http://www.osti.gov/contact.html

This report was prepared as an account of work sponsored by an agency of the United States Government. Neither the United States Government nor any agency thereof, nor any of their employees, makes any warranty, express or implied, or assumes any legal liability or responsibility for the accuracy, completeness, or usefulness of any information, apparatus, product, or process disclosed, or represents that its use would not infringe privately owned rights. Reference herein to any specific commercial product, process, or service by trade name, trademark, manufacturer, or otherwise, does not necessarily constitute or imply its endorsement, recommendation, or favoring by the United States Government or any agency thereof. The views and opinions of authors expressed herein do not necessarily state or reflect those of the United States Government or any agency thereof. 


\title{
Evidence-Based Background Material Underlying Guidance for Federal Agencies in Implementing Strategic Sustainability Performance Plans
}

\author{
Implementing Sustainability: \\ The Institutional-Behavioral Dimension
}

January 2011

(Updated June 2013)

Prepared by:

\author{
Elizabeth L. Malone ${ }^{1}$ \\ Tom Sanquist ${ }^{1}$ \\ Amy K. Wolfe ${ }^{2}$ \\ Rick Diamond ${ }^{3}$ \\ Christopher Payne ${ }^{3}$ \\ Jerry Dion ${ }^{4}$
}

\footnotetext{
${ }^{1}$ Pacific Northwest National Laboratory

${ }^{2}$ Oak Ridge National Laboratory

${ }^{3}$ Lawrence Berkeley National Laboratory

${ }^{4}$ U.S. Department of Energy
}

Prepared for:

Federal Energy Management Program

U.S. Department of Energy 
(THIS PAGE LEFT BLANK INTENTIONALLY) 


\section{ACKNOWLEDGEMENT}

The work presented in this document was funded by the U.S. Department of Energy's (DOE) Federal Energy Management Program (FEMP). Authors benefitted greatly from the work of two exceptional student interns, Stephanie A. Wang and Eric L. Dixon, and a careful review by Barry L. Shumpert

\section{SUMMARY}

This document is part of a larger, programmatic effort to assist federal agencies in taking action and changing their institutions to achieve and maintain federal sustainability goals, while meeting their mission goals. FEMP is developing guidance for federal agency efforts to enable institutional behavior change for sustainability, and for making sustainability "business as usual." The driving requirement for this change is Executive Order (EO) 13514, Federal Leadership in Environmental, Energy, and Economic Performance. FEMP emphasizes strategies for increasing energy efficiency and renewable energy utilization as critical components of attaining sustainability, and promotes additional non-energy action pathways contained in EO 13514.

This report contributes to the larger goal by laying out the conceptual and evidentiary underpinnings of guidance to federal agencies. Conceptual frameworks focus and organize the development of guidance. We outline a series of progressively refined conceptual frameworks, including a multi-layer approach, key steps in sustainability implementation, a process view of specific approaches to institutional change, the agency Strategic Sustainability Performance Plans (SSPPs), and concepts related to context-specific rules, roles and tools for sustainability. Additionally, we tap pertinent bodies of literature in drawing eight evidence-based principles for behavior change. These principles are important foundations upon which to build in selecting strategies to effect change in organizations. Taken together, this report presents a suite of components that inform the training materials, presentations, web site, and other products that provide guidance to federal agencies. 
(THIS PAGE LEFT BLANK INTENTIONALLY) 


\section{CONTENTS}

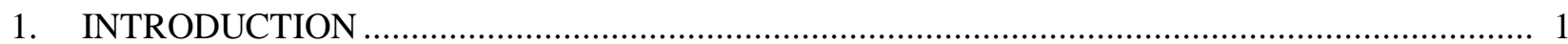

2. FRAMEWORKS FOR INSTITUTIONAL BEHAVIOR CHANGE TO PROMOTE SUSTAINABILITY IN FEDERAL AGENCIES 3

$2.1 \quad$ Frameworks are ways to understand, focus, and organize .................................................................

2.2 Action-oriented institutional change framework ..................................................................................

2.3 Frameworks that inform the action-oriented institutional change framework............................

2.3.1 Multi-layered human and organizational behavior framework ................................................ 4

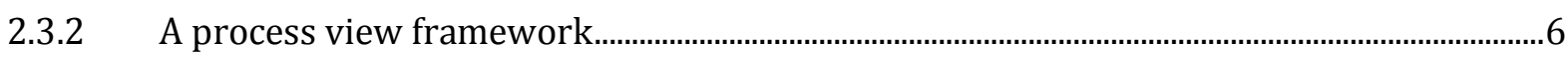

2.3.3 Agency Strategic Sustainability Performance Plans as a framework ......................................7

3. INSTITUTIONAL CONTEXT_-RULES, ROLES, AND TOOLS ........................................... 9

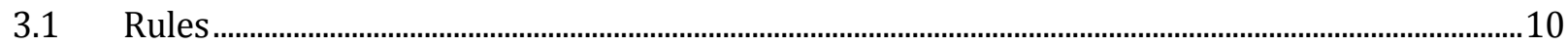

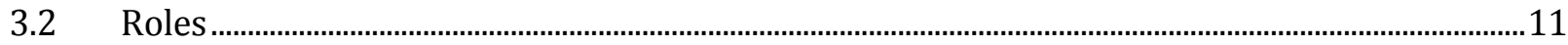

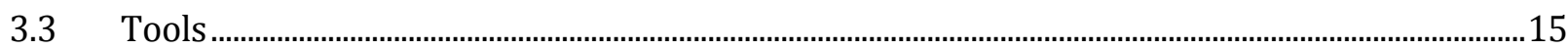

3.3.1 Accounting, reporting, and compliance..................................................................................15

4. EVIDENCE-BASED PRINCIPLES TO GUIDE THE SELECTION OF STRATEGIES FOR INITIATING AND MAINTAINING INSTITUTIONAL CHANGE ..........................................17

4.1 The Social Network and Communications Principle...........................................................................17

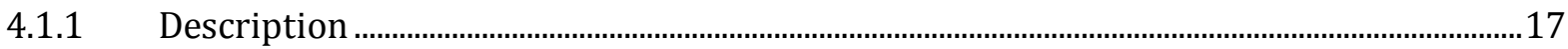

4.1.2 Practical advice for program design and implementation ....................................................18

4.1.3 Examples from the literature that support this principle .......................................................18

$4.2 \quad$ The Multiple Motivations Principle........................................................................................................20

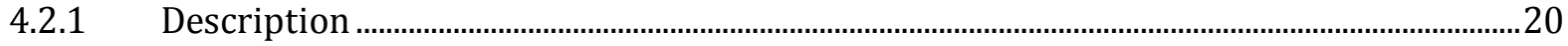

4.2.2 Practical advice for program design and implementation ........................................................20

4.2.3 Examples from the literature that support this principle .......................................................20

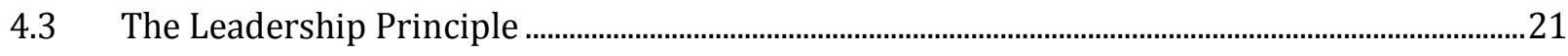

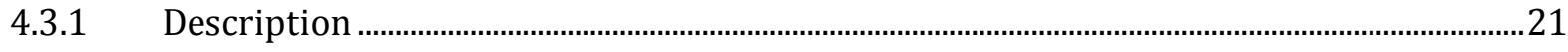

4.3.2 Practical advice for program design and implementation .......................................................21

4.3.3 Examples from the literature that support this principle ..........................................................22

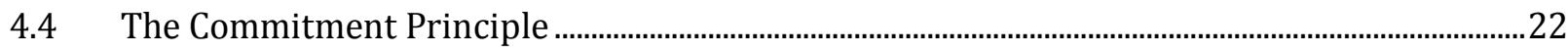

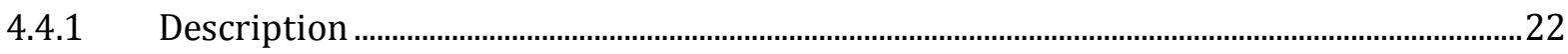

4.4.2 Practical advice for program design and implementation .....................................................22 
4.4.3 Examples from the literature that support this principle .......................................................23

4.5 The Information and Feedback Principle ….................................................................................................23

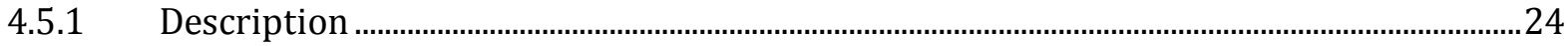

4.5.2 Practical advice for program design and implementation ......................................................24

4.5.3 Examples from the literature that support this principle .......................................................24

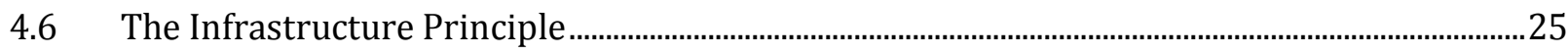

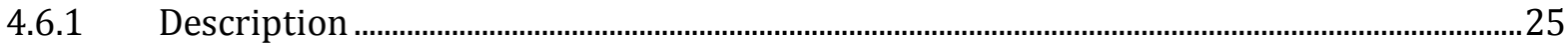

4.6.2 Practical advice for program design and implementation ..................................................26

4.6.3 Examples from the literature that support this principle ...........................................................26

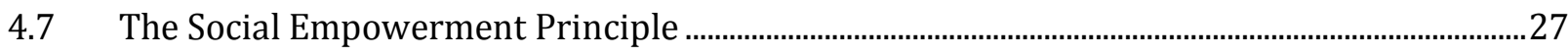

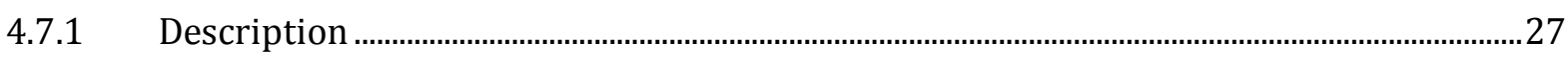

4.7.2 Practical advice for program design and implementation .....................................................2

4.7.3 Examples from the literature that support this principle ............................................................27

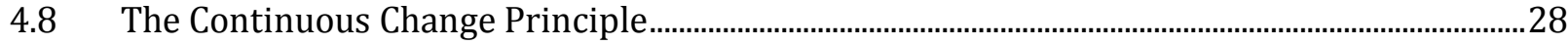

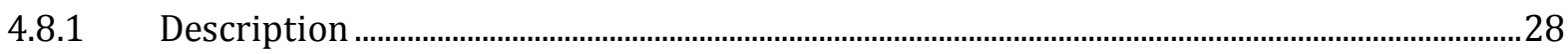

4.8.2 Practical advice for program design and implementation ....................................................28

4.8.3 Examples from the literature that support this principle ......................................................28

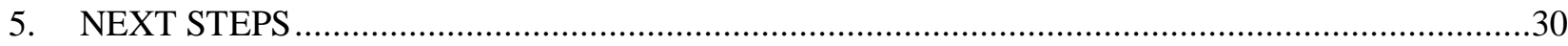

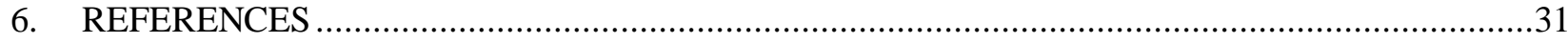




\section{LIST OF TABLES}

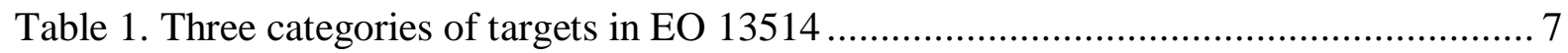

Table 2. Illustrative linkages among organizational roles, players, actions, sustainability impact, and strategies for effecting behavior change ......................................... 14 
(THIS PAGE LEFT BLANK INTENTIONALLY) 


\section{LIST OF FIGURES}

Figure 1. The action-oriented institutional change framework depicts steps to achieving sustainability goals and a continuing cycle of improvement..........................................4

Figure 2. Multi-level social-behavioral framework for sustainability implementation. ...............5

Figure 3. A process view of achieving sustainability goals through social science-based

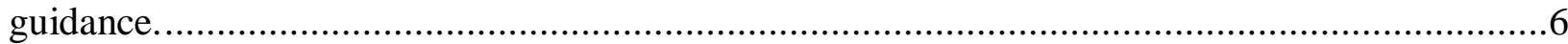

Figure 4. An integrated strategy to change rules, roles, and tools facilitates the transition from current agency operations to achieving sustainability goals.

Figure 5. Hypothetical organizational structure for departmental implementation of EO 13514 reporting. 
(THIS PAGE LEFT BLANK INTENTIONALLY) 


\section{ACRONYMS AND ABBREVIATIONS}

$\begin{array}{ll}\text { AFV } & \text { Alternative fuel vehicle } \\ \text { BECC } & \text { Behavior, Energy, and Climate Change } \\ \text { CEQ } & \text { Council on Environmental Quality } \\ \text { CFL } & \text { Compact fluorescent light } \\ \text { DHS } & \text { Department of Homeland Security } \\ \text { DOD } & \text { Department of Defense } \\ \text { DOE } & \text { Department of Energy } \\ \text { DOT } & \text { Department of Transportation } \\ \text { EERE } & \text { Energy Efficiency and Renewable Energy } \\ \text { EMS } & \text { Environmental Management System } \\ \text { EPA } & \text { Environmental Protection Agency } \\ \text { EPEAT } & \text { Electronic Product Environmental Assessment Tool } \\ \text { EO } & \text { Executive Order } \\ \text { FEMP } & \text { Federal Energy Management Program } \\ \text { GHG } & \text { Greenhouse gas } \\ \text { GSA } & \text { General Services Administration } \\ \text { IT } & \text { Information technology } \\ \text { SSO } & \text { Senior Sustainability Officer } \\ \text { SSPP } & \text { Strategic Sustainability Performance Plan } \\ \text { WBCSD } & \text { World Business Council on Sustainable Development }\end{array}$


(THIS PAGE LEFT BLANK INTENTIONALLY) 


\section{INTRODUCTION}

Signs of interest in the effects of individual and organizational behavior on energy use have gathered steam in recent years. One notable example is the string of professional conferences on Behavior, Energy and Climate Change (BECC), with the participant list growing to more than 700. Another example is a congressional hearing on the subject, convened by Representative Brian Baird in November 2009. A third example is the U.S. Department of Energy's (DOE's) multi-laboratory teams focused on institutional and individual behavior within its Energy Efficiency and Renewable Energy (EERE) Office (EhrhardtMartinez and Laitner 2010). Several major reports have been issued (see Ehrhardt-Martinez and Laitner 2008), and the phrase "behavioral wedge" has been coined to describe a share of emissions reductions that could be realized by behavioral change (Dietz et al. 2009; see also Pacala and Socolow 2004).

German researchers (Broc et al. 2006) searched for studies of energy efficiency efforts in commercial buildings in the service sector and found more than 20; their example table lists 9 studies in Europe and Canada, and an in-depth review describes a campaign that achieved 10 percent savings - without making technological changes - using an initial survey, information meetings and posters, signing individual commitments, follow-up surveys, and communicating feedback to reinforce changed behaviors.

Three recent studies suggest that the potential behavior-related energy savings (or greenhouse gasGHG - emission reductions) in the residential sector are significant - in the range of 20-30\% of current residential sector energy demand (Gardner and Stern 2008, Laitner et al. 2009, WBCSD 2010). The World Business Council on Sustainable Development (2010:62) estimates that "wasteful behaviour can add one-third to a building's designed energy performance, while conservation behaviour can save a third." Although the majority of studies focus on residential buildings and behavior, some parallels exist for workplace buildings. In both types of buildings, human use and control of energy-efficient systems will determine the actual energy savings, not the mere presence or absence of certain technologies. People may find ingenious ways to sidestep or decommission new technologies — or they may find ways to amplify the energy savings of new technologies that increase comfort or convenience, and improve workplace lighting or social interactions.

Notwithstanding the potential for behavioral change, research on energy use and how to reduce such use has focused predominantly on technological change - with the assumption that adoption of more energyefficient technologies will almost automatically result in reduced energy use. In other words, behavioral change will follow in due course from changes in technology. Unfortunately, expectations of energy savings have frequently not been fulfilled. Vehicle miles traveled in the United States simply increased to compensate for energy-efficient engines. Model buildings often do not realize projected efficiency gains. Individuals do not use - or misuse - tools such as programmable thermostats. And so on.

Behind the view that technology leads un-problematically to behavioral change lies the rational actor model, which assumes that people make choices based on the lowest cost for the service they need. Thus, if they need electricity, they will purchase it from the cheapest source. The issue of energy efficiency, then, consists of providing energy sources that are both efficient and cheaper than less efficient technologies. Of course, if price were the only factor in any decision, this assumption would be correctbut a host of factors such as availability of alternatives, convenience, other features, and many more, influence decisions.

Critiques of the rational actor model are legion. However, with a long history of using the flawed technological and rational model, researchers today know more about what doesn't work than what does. 
In short, methods unlikely to work for sustainability programs include the following: disseminating via mailbox inserts or email new rules regarding sustainability, appealing to only one motivation, failing to provide leadership, providing no co-benefits, making no provision for social network influences, and not following up.

What we do know is that, in the real world, people rarely purchase goods and services purely on economic considerations; instead, status, convenience, social networks, identity, values, and culture all play large roles - and people may, in fact, purchase the most expensive option and/or the least sustainable option. We have a developing body of research, both theoretical and based on case studies, that suggests a promising set of principles for how to design and implement energy efficiency and sustainability programs. However, no magic formula exists.

Former Secretary of Energy Steven Chu called upon DOE employees and contractors to contribute to achieving the federal government's energy and environmental goals through personal actions in the workplace, citing energy savings of up to 15 percent at low cost through behavior change programs in the private sector. While these savings rates are anecdotal, they indicate a potential source of savings that should be pursued. To support Secretary Chu's call to action, and to enable all agencies to take effective institutional and behavior change actions, DOE's Federal Energy Management Program (FEMP) is developing evidence-based training, program design guidance, and information and outreach activities and materials. These resources aim to support agencies as they implement the Strategic Sustainability Performance Plans (SSPPs) required by Executive Order (EO) 13514. FEMP will assist federal agencies in implementing their SSPPs more effectively, through evidence-based improvements to organizational design, operation, and functioning.

One goal of this project is to develop effective, evidence-based guidance for federal agencies seeking to incorporate organizational changes to achieve their energy efficiency, renewable energy, waste reduction, and other sustainability goals. The guidance will be based on social science research; comprehensive, but sensitive to diverse agencies, and evolving agency missions and needs; and responsive to information and feedback elicited from "users" from multiple federal agencies. The FEMP team is also compiling a set of strategies that can be implemented in the near and longer terms to achieve SSPP goals.

This document represents one portion of our larger programmatic effort. Specifically, it lays out the foundational concepts, frameworks, and evidence-based principles that underlie the multiple guidanceoriented products produced by this team. 


\section{FRAMEWORKS FOR INSTITUTIONAL BEHAVIOR CHANGE TO PROMOTE SUSTAINABILITY IN FEDERAL AGENCIES}

\subsection{Frameworks are ways to understand, focus, and organize}

The term "framework" is commonly employed in discussions of complex problems, but often evokes different meanings and interpretations. While most people have an intuitive understanding of the term, here we define framework on the basis of how it is used in qualitative research: "any empirical or quasiempirical theory of social/psychological processes at a variety of levels (e.g., grand, mid-range, and explanatory) that can be applied to the understanding of phenomena" (Anfara, 2008). Since we are concerned with institutional and individual behavior, there is a clear utility in considering social and psychological processes and various levels. While our objective is to facilitate organizational implementation of sustainability practices, we will be formulating that guidance in terms of macro ("grand") and mechanistic ("explanatory") processes and levels derived from the social science literature.

A framework is generally considered as providing a viewpoint or "lens" with which to observe and work within a particular domain. This focus provides a means for defining questions asked and data collected, can help to reduce subjectivity and bias (especially important in social/psychological research), and provides a tool for reconciling measurement, data and analysis in terms of theory (Anfara, 2008). Additional functions of a framework include establishing a common basis for dialogue about complex problems, and illustrating areas of strength and weakness in the underlying theory or applications.

The goal of the current project is to provide evidence-based social science guidance to agencies as they develop approaches for achieving their energy efficiency, renewable energy, waste reduction, and other sustainability goals. A research framework facilitates understanding the complex organizational activities associated with achieving the goals. Guidance is only useful to the extent that it is relevant, and the research framework exercise is aimed at developing a better understanding of how and where to direct our guidance. As the material in subsequent sections illustrates, responding to and implementing the requirements of EO 13514 crosses multiple government agency boundaries, levels within agencies, personnel roles, and involve a variety of means.

\subsection{Action-oriented institutional change framework}

In developing evidence-based guidance for federal agencies, we needed to create a framework that integrates, organizes, and translates many perspectives and sources of information into actions - stepsthat sustainability program designers and planners could take. We introduce our resulting framework and then describe other frameworks from which we drew. Our institutional change framework depicts institutional change as a process that includes the instigation of change and a cycle of continuous improvement. The framework contains the five generic steps for institutional change shown in Figure 1. These steps begin with goal-setting and move to an assessment of that institution's context (see Section 3 for more on the rules, roles, and tools that constitute institutional context). Based on the goal and institutional context, the next steps are to develop and implement action plans. We envisage that the eight literature-derived principles for behavioral and institutional change (see the Appendix) will aid in the selection of context-specific strategies that align with the previously articulated goals. Interim and posthoc measurement and evaluation results feed into refined or new goal-setting, and the cycle begins again. 


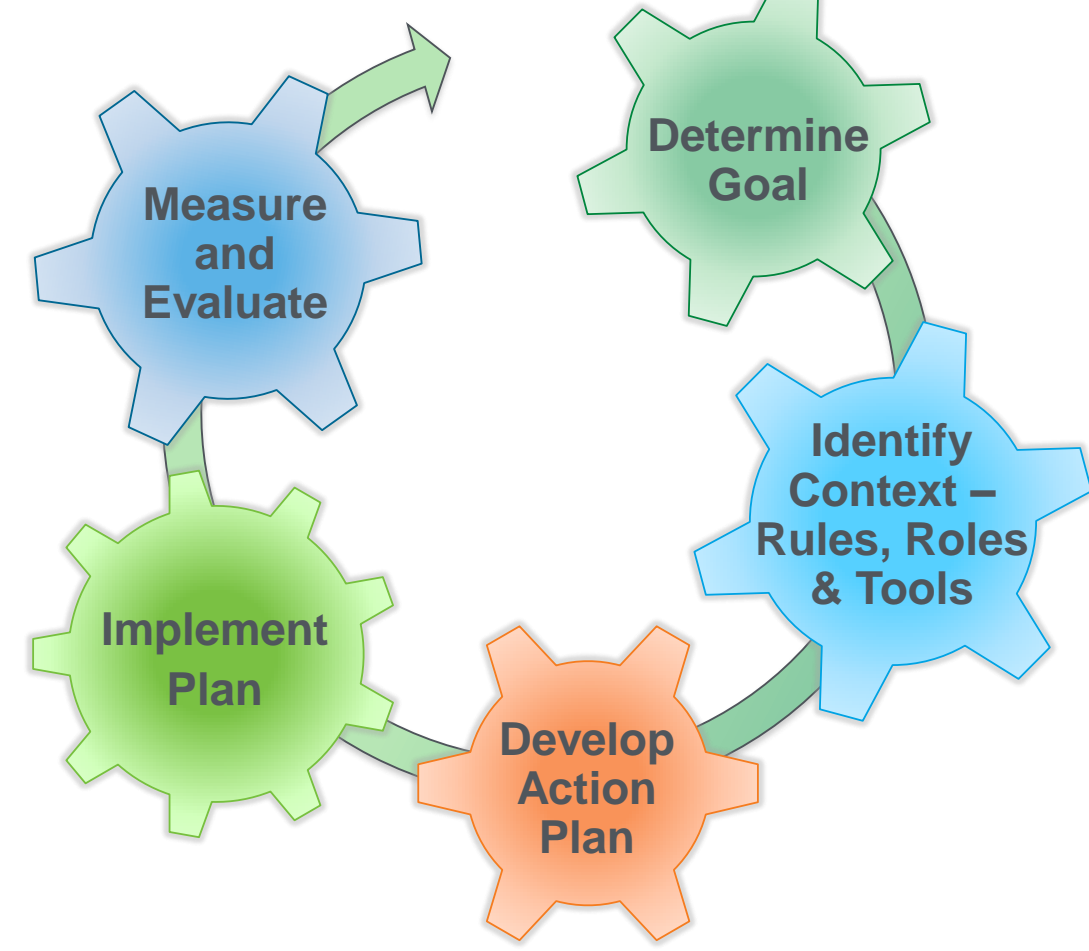

Figure 1. The action-oriented institutional change framework depicts steps to achieving sustainability goals and a continuing cycle of improvement.

\subsection{Frameworks that inform the action-oriented institutional change framework}

A variety of research-oriented frameworks and SSPP-specific information were integrated into the actionoriented institutional change framework just described. The following subsections summarize those inputs into our framework.

\subsubsection{Multi-layered human and organizational behavior framework}

Our work is based on a fundamental framework of human and organizational behavior. Sustainability in organizations will require changes at multiple levels and take place over a considerable period of time. Simple exhortations to individuals will not result in enduring change unless they are embedded in a more fundamental shift of organizational culture. Examples of such changes come from the long-term modifications of organizational culture, processes and individual behavior in areas such as safety and security (e.g., IAEA, 2002). This multi-layered framework is depicted in Figure 2. 


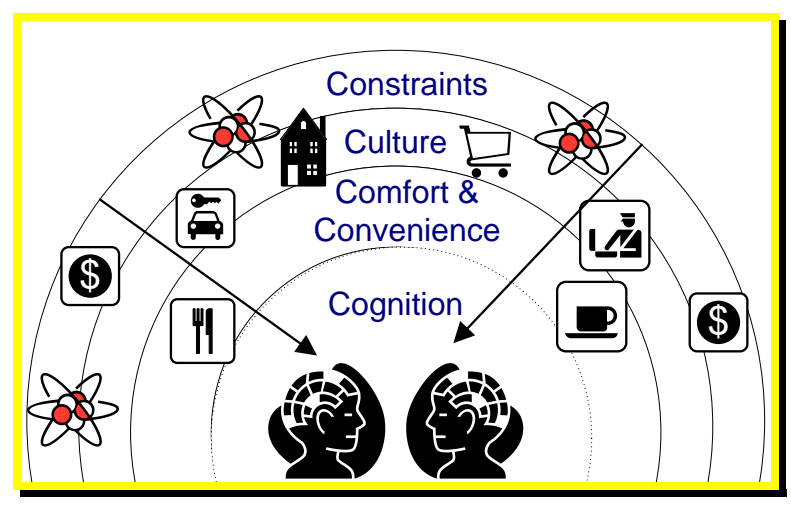

Figure 2. Multi-level social-behavioral framework for sustainability implementation.

The key elements of this model include constraints in the physical, financial and political environment on the sustainability approaches that can or will be designed. Constraints can apply across multiple system levels - social, system, workgroup, program and device. These constraints interact with the culture in which sustainability implementation takes place - the organizational, institutional and end user values and attitudes concerning technologies and energy. Comfort and convenience are key motivators at the level of groups and individuals; cognition refers to the individual mental processes associated with carrying out specific sustainability tasks, such as powering down workstations and planning ahead for travel.

These model elements interact. Culture, for example, can create design constraints in terms of what people will or won't do, based on existing mental models (cognition) of the comfort and convenience various sustainability actions might represent. The utility of this framework is that it can be used to represent sustainability program design concerns across a range of influences. It can provide a basis for dialogue among the multiple stakeholders engaged in development, including agency leads, work group constituents, and individuals, as well as identifying levels for application of social-behavioral principles.

Because there are various ways to conceptualize the diverse and complex aspects of this work, we will likely need to use multiple frameworks that evolve over time as we learn more about organizational sustainability implementation. To list just a few examples, frameworks might address the sequential flow of activity, organizational hierarchies, personnel, sustainability approaches (e.g., efficiency, renewables), behavioral principles and tools for implementation. Some of these might be eventually developed as subframeworks, but for the initial approach we will blend these aspects in terms of how they are addressed by the SSPPs.

Our initial strategy for framework development and application is to follow the organizational lines and processes indicated by EO 13514, including the nine reporting and sustainability goals, and the accountabilities established. The EO requirements are further elaborated in individual agency SSPPs, which serve as an initial basis for developing our framework for supporting organizational change with social science-based principles. 


\subsubsection{A process view framework}

An integrating framework that portrays a process flow for achieving the EO 13514 goals is shown in Figure 3. This framework shows that the key product of the current research effort, FEMP guidance, is developed in terms of EO 13514 requirements and social science research principles. Agencies responsible for implementing the EO will use a variety of strategies for change that have a behavioral basis, targeting various rules such as contracting procedures, roles such as facilities manager, and tools such as measurement and training. Rules, roles and tools are discussed further below.

The implementing strategies (those shown are illustrative, not exhaustive) will lead to various efficiency and conservation processes, enabled and facilitated by longer-term cultural and institutional changes. The various sustainability goals described in the EO are shown as the outcomes of this process.

Social science principles will be applied to specific behavioral interventions and tools, including those shown in Figure 3 and others that are discovered by outreach to selected agencies. For example, information and measurement will initially serve a reporting function for EO compliance, but can also be presented in such a way as to be useful for monitoring and changing consumption. This involves the general process of feedback, which can be developed to best application through knowledge of behavioral principles. In a similar way, our work can provide principled approaches for training, leadership, procedure development, incentives, and methods of evaluation and behavioral maintenance

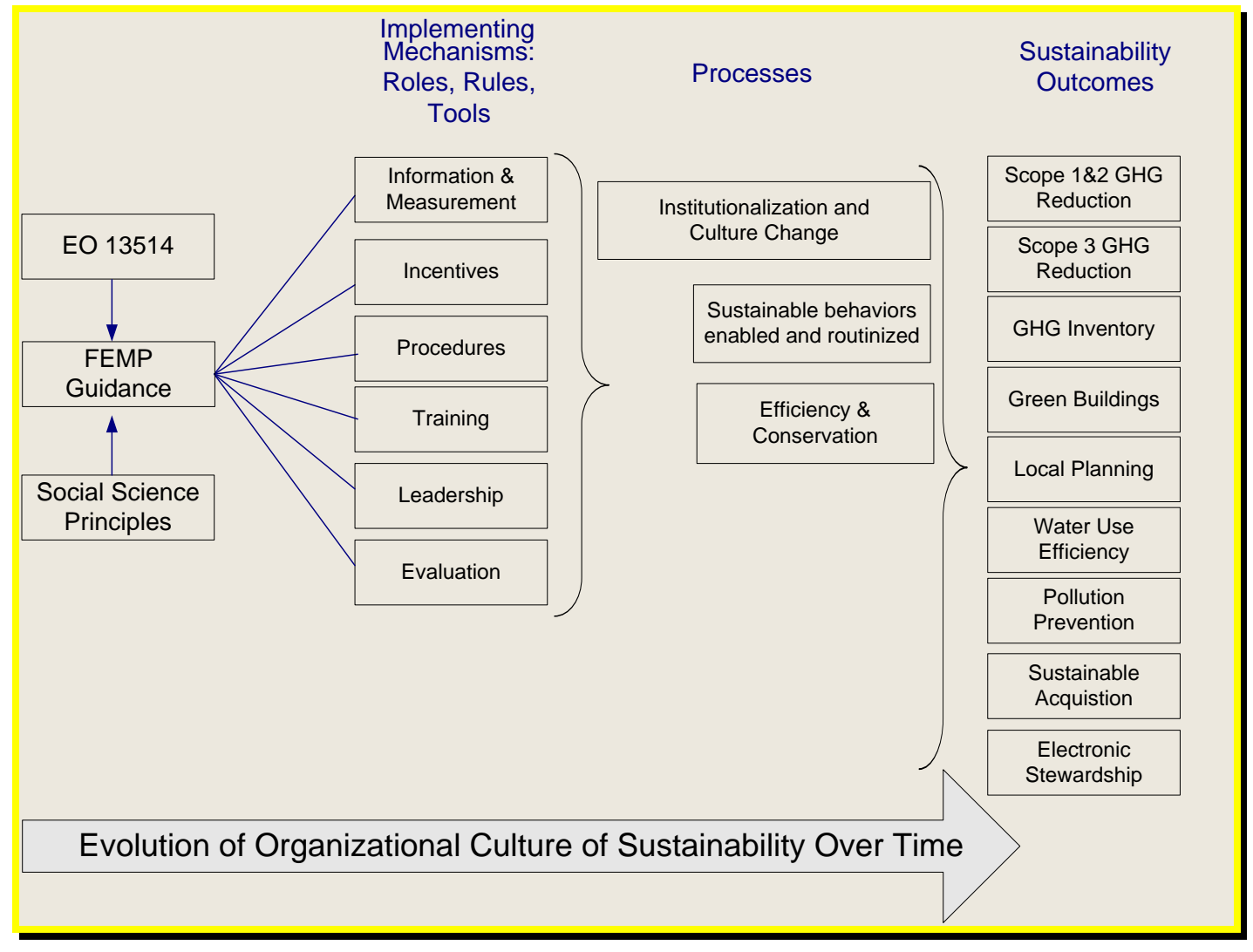

Figure 3. A process view of achieving sustainability goals through social science-based guidance. 


\subsubsection{Agency Strategic Sustainability Performance Plans as a framework}

On September 9, 2010, federal agencies submitted their first SSPPs which "work to achieve the environmental, economic and energy goals called for in" EO $13514^{1}$. The SSPPs tend to follow the structure of the EO, and provide additional details concerning the means by which agencies will achieve the sustainability targets. As described in the EO, there are three general categories of target in the SSPPs: quantitative reduction goals, non-quantitative reduction goals, and management strategies to ensure sustainability (see Table 1$)^{2}$

Table 1 . Three categories of targets in EO 13514

Quantitative targets

- Covered buildings should achieve a 3\% reduction in energy intensity per year (starting in FY 2006) leading to a 30\% reduction in 2014 compared to FY 2003 (E.O. 13423, EPACT 2005 and EISA 2007).

- Reduce petroleum consumption by $2 \%$ per year through FY2020 (applies to agencies with fleets of more than 20 vehicles) (Baseline FY2005).

- Reduce by $2 \%$ annually potable water intensity ( $26 \%$ total by FY 2020 - FY2007 baseline) and industrial, landscaping, agricultural water intensity ( $20 \%$ total by FY2020 - FY2010 baseline).

- Achieve $50 \%$ or higher diversion rate by FY2015 of non-hazardous solid waste and of construction and demolition materials and debris.

- Ensure at least $15 \%$ of existing buildings and leases (>5,000 gross sq ft) meet the Guiding Principles for Federal Leadership in High Performance and Sustainable Buildings (http://www.energystar.gov/ia/business/Guiding_Principles.pdf) by FY2015, with continued progress towards $100 \%$.

- Ensure $95 \%$ of all new contracts, including non-exempt contract modifications, require products and services that are energy-efficient, water-efficient, biobased, environmentally preferable, non-ozone depleting, contain recycled content, non-toxic or less-toxic altematives.

Non-quantitative targets

- Increase renewable energy and renewable energy generation on agency property.

- Pursue opportunities with vendors and contractors to reduce GHG emissions (i.e., transportation options and supply chain activities).

- Reduce building energy intensity.

- Ensure all new federal buildings that enter the planning process in 2020 and thereafter are designed to achieve zero-net-energy standards by 2030.

- Use low GHG emitting vehicles, including AFVs; optimize the number of vehicles in agency fleets.

- Implement water management strategies including water-efficient and low-flow fixtures.

- Implement source reduction to minimize waste and pollutant generation.

- Decrease use of chemicals directly associated with GHG emissions.

- Participate in transportation planning; recognize existing infrastructure in regions/communities.

- Ensure procurement preference for EPEAT-registered electronic products.

Management strategies

- Develop and implement innovative, agency-specific policies and practices to reduce scope $3 \mathrm{GHG}$ emissions in agency operations.

- Manage existing buildings to reduce energy, water, and materials consumption.

- Implement and achieve objectives in EPA's Stormwater Management Guidance (§14).

- Reduce paper use and acquire paper containing at least $30 \%$ postconsumer fiber.

- Minimize the acquisition, use, and disposal of toxic and hazardous materials.

- Use environmentally sound practices for the disposition of all excess or surplus electronic products.

- Procure Energy Star and FEMP-designated electronic equipment.

- Continue implementation of existing EMS programs.

\footnotetext{
${ }^{1} \mathrm{http} / / / \mathrm{www}$. whitehouse.gov/administration/eop/ceq/sustainability/plans

${ }^{2}$ Source: http://www.fedcenter.gov/programs/eo13514/
} 
Initial agency SSPPs began to define specifically how GHG reduction and other sustainability goals are to be achieved. While a comprehensive comparison is beyond the scope of the current effort, a review by our social science team has identified several common approaches across agencies that could benefit from applying behavior-based principles in their implementation. These approaches include:

- Training and awareness

- Metering and feedback

- Changing transportation patterns

- Awards and incentives

- Local/regional planning

- Information technology (IT) management

Examples that follow are drawn from the original SSPPs submitted by agencies in 2010. For instance, training and awareness programs include educating employees about the relationship between their actions and waste reduction, increased energy efficiency, potential use of renewable energy sources, and the impact on GHG reduction. Other training focuses on behaviors such as turning off various office energy consuming equipment (e.g., Department of Homeland Security [DHS]); and broader agency-wide "greening" initiatives, including energy conservation and waste reduction, to "foster culture change that is directed to all employees with an emphasis on key stakeholders and decision-makers" (Department of Transportation [DOT]).

Metering and feedback approaches often are described in terms of granularity of data (e.g., sub-metering at the level of workgroups or individual spaces) and "dashboards" to present energy consumption data related to various end uses. The working assumption in these approaches is that providing information via better measurement will make energy use visible, and thus stimulate behaviors that will reduce energy use.

Changing transportation patterns encompass both business travel and employee commuting. Various solutions for commuting are mentioned in the SSPPs we reviewed, including making workplaces more bicycle-friendly, subsidizing mass transit, reducing parking subsidies, and promoting telework. SSPPs we reviewed express the intent to reduce the overall amount of business travel conducted. In addition the documents incorporate means for reducing GHG emissions while on travel by promoting various "green travel" options.

Awards and incentive programs would be used by agencies to stimulate competition among organizational units for GHG reduction, and would likely incorporate some of the training and metering/feedback described above.

Local and regional planning activities are described in SSPPs as ways to engage federal agencies and local stakeholders to address issues of workforce planning, recruiting and retention in relation to employee household location, and ultimately, site planning for new facilities.

IT management encompasses a host of approaches to reduce energy consumption by computer technology, and involves such approaches as ensuring Energy Star equipment purchases, mandated power settings, reduction of personal printers, and proper disposal of excess or surplus equipment. 


\section{INSTITUTIONAL CONTEXT-RULES, ROLES, AND TOOLS}

One of the distinctive features of the action-oriented institutional change framework introduced in Section 2.2 is its specification of "institutional context" and three key components of that context — rules, roles, and tools (Figure 4). The interactions among formal and informal rules that govern processes and practices in federal workplaces, the network of roles necessary to instigate and maintain sustainability, and the infrastructural tools - technologies, systems, and processes - available to managers, workgroups and individuals as they implement sustainability plans are essential to effecting significant and lasting change. This section discusses some of the considerations associated with more detailed analysis of rules, roles and tools, to provide context for guidance development.

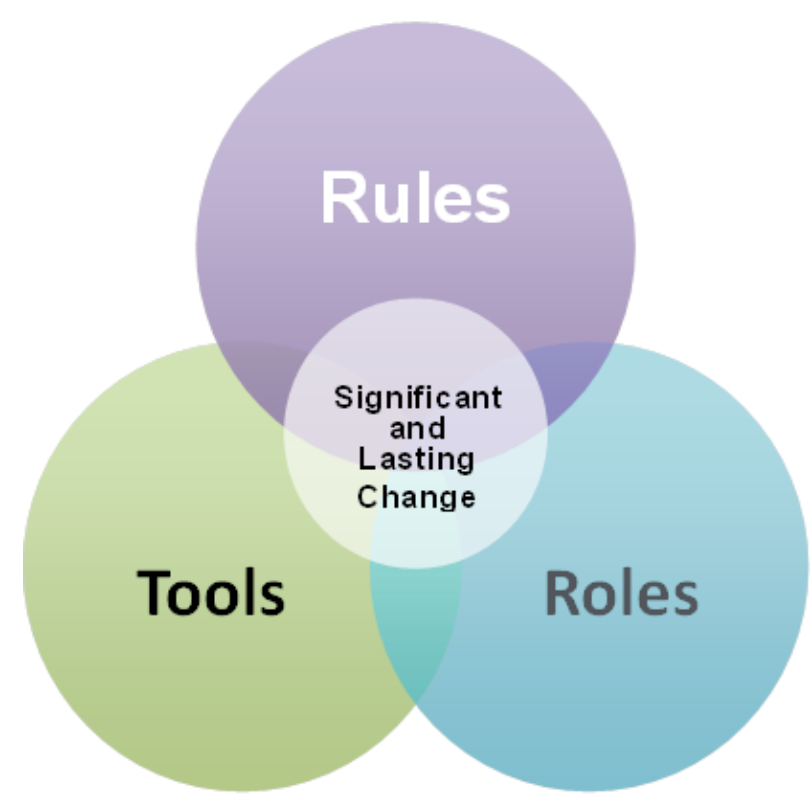

Figure 4. An integrated strategy to change rules, roles, and tools facilitates the transition from current agency operations to achieving sustainability goals.

Assessments of institutional context are crucial for developing and implementing effective plans to achieve specified sustainability goals. Such assessments allow planners to understand the physical, social, and institutional "system" in which they are operating and tailor their plans accordingly. For example, in designing a change program focused on sustainability and energy efficiency, federal agencies will need to assess the starting points of their agencies. Agencies such as DOE and the General Services

Administration (GSA) already had at least the beginnings of an energy efficiency culture by 2011, which they could build upon. A history of visible and successful You Have the Power campaigns, FEMP award winners, and identified Energy Champions could provide familiarity and possibly could signal cultural acceptance of energy efficiency as a value. Agencies that traditionally trumped sustainability and energy efficiency with their mission requirements had different starting points - and needed to establish connections instead of oppositions between mission and sustainability/energy efficiency. Still other agencies that had no particular stance toward sustainability and may have seen sustainability goals or requirements as unnecessary or burdensome had a third starting point. 


\subsection{Rules}

Rules govern the behavior of individuals, institutions, and organizations. Rules can be formal or informal, tacit or explicit. Achieving the sustainability goals specified in EO 13514 is subject to rules of all these types. Our team plans to identify and map existing rule sets as well as those yet to be developed. The general discussion of rules, below, describes elements that we are incorporating into the guidance we are developing on institutional and behavioral change.

The simplest rule is a written directive to be followed by each individual, such as a sign that says, "Turn the lights out when you leave." Management has spoken and may expect that individual behaviors will automatically align. However, issuing simple directives does not necessarily translate into action. Responses may vary in the following two situations. A supervisor may reinforce the message in the sign by saying in a meeting (or writing an email) that she expects compliance. Or a manager may merely pass down a requirement, neither knowing nor caring whether people comply.

Beyond the simplest example, rules quickly become complicated. New or updated programs are often accompanied by new sets of rules for accomplishing new or revised goals. The emphasis on lighting public spaces (such as parking lots) for safety may give way to a program for energy efficiency, where some the lights are turned off or their hours are curtailed. That same new program may prohibit small refrigerators or heaters in offices, cut parking subsidies while increasing public transportation subsidies, and institute work-at-home programs.

Depending on how new programs and rules are implemented and the office culture, employees may (1) ignore the new rules and continue with accustomed practices, (2) comply to the extent that the rules are convenient or enforced, or (3) adopt the spirit of the program and go beyond compliance. Implementation might vary from an impersonal handout to all-out enthusiasm communicated through personal contacts, rewards, and feedback. The implementation of rules should match the workplace culture, however. Implementation methods successful in a "rules are rules" culture (e.g., the military) would be unlikely to produce similar outcomes in a "question authority" culture (e.g., one more associated with rebellious youth - or scientists). These are examples of workplace cultural rules; the workplace usually has many such rules, some overlapping or even seemingly contradictory.

Thus, formal, written rules are accompanied by nonverbal messages and rules that usually are more powerful than the formal rules themselves. The unwritten rule, "We always greet each other in the hallways," is quickly communicated by example — as might be the rule, "We always turn out lights when we leave." If there is a cultural rule that staff resent management telling them what to do, written rules by themselves will stand but a poor chance of gaining compliance, and a supervisor who ignores this cultural rule may find himself ignored.

There are many definitions of the term "institution" (see box). Many social scientists would say that institutions are sets of tacit rules - rules about how people treat one another, what can be said and what cannot be said, how decisions are made and justified, and so on. 
Institutions and Rules

Institutions...

- regulate behavior via socially approved mechanisms such as the rule of law and the accountable exercise of power.

- $\quad$ are patterns of routinized behavior, "the more enduring features of social life" (Giddens 1984:24).

- $\quad$ are cognitive and normative structures that stabilize perceptions, interpretations, and justifications.

- determine what is appropriate, legitimate, and proper, they define obligations, self-restraints, rights, and immunities, as well as the sanctions for unacceptable behavior.

- structure the channels through which new ideas are translated into policy and new challenges receive a government response.

Individuals unload their decision making, at least to some extent, onto institutions (Douglas 1986).

Standards are a type of social institution in that they are "recurrent patterns of behavior that help to coordinate human activity" (Garud and Karnøe 2001).

Adapted from O'Riordan et al. 1998

Initial SSPPs indicated that many new rules and procedures could be implemented in pursuit of sustainability goals. Straightforward examples come from the business travel and workstation electronics domain. A common theme across the SSPPs reviewed is a focus on reduced or "green" travel, and on power settings for electronics. Both of these areas would easily lend themselves to top-down mandatory rules, which may be counterproductive in various settings, as discussed above. The guidance we are developing is sensitive to organization-specific workplace culture, and does not assume that strategies successful in one setting are appropriate for all settings. Similarly, our guidance emphasizes formal and informal rules because we understand that (a) the existence of rules does not dictate whether or how those rules will be implemented and (b) informal rules may be more powerful than formal rules in affecting behavior.

\subsection{Roles}

EO 13514 requires that agencies designate a Senior Sustainability Officer (SSO) as the position ultimately responsible for carrying out the order requirements, including reporting and monitoring. Within individual agency SSPPs, the functions are delegated in a hierarchical manner reflecting organizational structure. For instance, two generic roles defined for the reporting effort include GHG lead, and GHG data collector. ${ }^{3}$ Figure 5 illustrates a hypothetical organization of these roles.

\footnotetext{
${ }^{3}$ http://www.fedcenter.gov/_kd/go.cfm?destination=Page\&Pge_ID=3778
} 


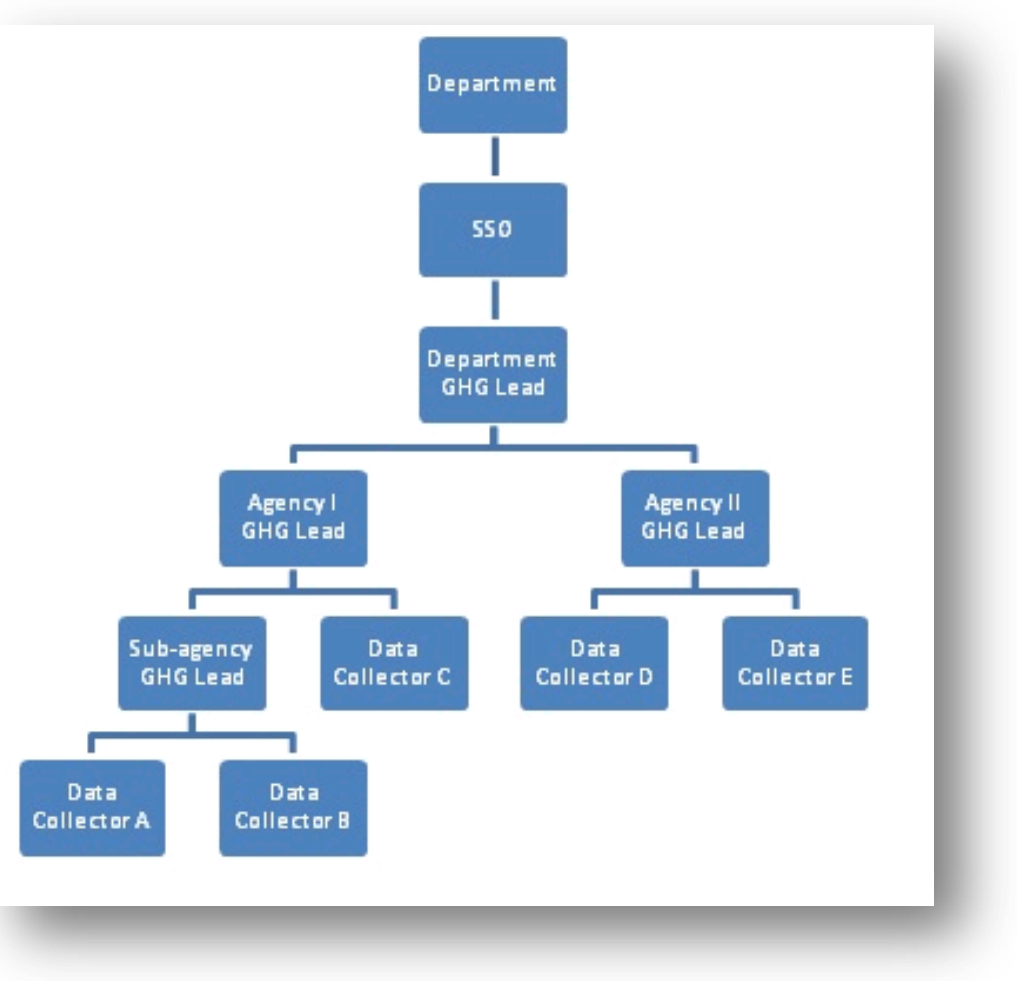

Figure 5. Hypothetical organizational structure for departmental implementation of EO 13514 reporting.

The GHG reporting chain is one conceptualization of roles, which may overlap with other business process owners concerned with implementing reduction strategies. Identifying these individuals and the specific approaches that would benefit from behavior-oriented guidance will require deeper analysis of agency functional areas.

Examples of more offices or roles charged with sustainability are listed in the agency SSPPs, along with brief descriptions and possible role-based attitudes:

- Agency Head. Provides vision and overall leadership. Communicates key strategies and policy goals; performance expectations and priorities; and resource allocation priorities. Directs others to manage the effort. Ties sustainability to the agency mission at every opportunity.

- Chief Financial Officer. Reviews the costs and savings from proposed measures. Develops criteria for all expenditures. Skeptical of claims of energy savings.

- Procurement Officer. Establishes procedures for all agency procurement, including utility purchases. Is always looking for ways to reduces expenditures without compromising quality essential to agency mission.

- Building Manager. Oversees the operations and maintenance of the facilities. Sees job as minimizing comfort complaints by the building occupants. Reducing energy use is not in the job description.

- IT Director. Sets all policies relating to computer usage, security, back-up, and operations. Energy use may be the "cost of doing business."

- Sustainability Champion. The advocate for all things green. Provides information on new strategies and ideas for reducing carbon.

- Union Representative. Oversees the actions in the workplace, looking out for the well-being of the employees. 
- Employees. Key players. Most employees primarily are focused on doing their jobs and carrying out the agency mission. By identifying and engaging those in influential or key positions, there will be broader impact on the rest of the employee base.

- Other Players identified by the team. Could include safety officers, environmental specialists, HR representatives, etc.

Organizational approaches to sustainability involving all levels of personnel are being implemented in diverse ways across the federal agencies. The SSPPs describe organizational structures, and roles and responsibilities related to sustainability.

A more detailed view of roles and their functions in relation to sustainability is shown in Table 2, which lists categories of organizational role, key players within those organizations, actions those players may take, the impact on energy consumption, and possible means for influencing behavior at these levels. The main point to emphasize here is that the term role can have a variety of meanings, from organization to individual, and that there are a variety of points of intervention on the scale of behavior change.

Moreover, it is important to assess what roles are essential for initiating, implementing, and perpetuating interventions intended to achieve sustainability goals. Overlooking key roles can undermine the potential success of an intervention. Take, for example, a seemingly obvious strategy of in-office bins with separate compartments for recyclables and landfill wastes. These bins could be considered important for reducing the volume of office wastes diverted to landfills. If planners assume that the key roles involved are "office staff," their strategy could prove far less successful than envisioned. Even if every office worker dutifully separates trash from recyclables, waste diversion goals cannot be met unless janitors also keep waste streams separate. Managers who supervise janitorial staff are key players insofar as they create conditions conducive to or that mediate against achieving waste diversion goals. 
Table 2. Illustrative linkages among organizational roles, players, actions, sustainability impact, and strategies for effecting behavior change

\begin{tabular}{|c|c|c|c|c|}
\hline $\begin{array}{l}\text { Organizational } \\
\text { roles }\end{array}$ & Players & Actions & $\begin{array}{l}\text { Impact on } \\
\text { sustainability }\end{array}$ & $\begin{array}{c}\text { Strategies for } \\
\text { changing behavior }\end{array}$ \\
\hline $\begin{array}{l}\text { Organizational } \\
\text { leaders (owners) }\end{array}$ & $\begin{array}{l}\text { Leaders, deputies, } \\
\text { chief operating or } \\
\text { financial officers, } \\
\text { building owners, } \\
\text { etc. }\end{array}$ & $\begin{array}{l}\text { Run agency, set } \\
\text { vision, model } \\
\text { culture, articulate } \\
\text { expectations, } \\
\text { review performance }\end{array}$ & $\begin{array}{l}\text { Set priorities for } \\
\text { energy reduction } \\
\text { relative to other } \\
\text { agency goals, } \\
\text { establish culture of } \\
\text { energy action \& } \\
\text { commitment }\end{array}$ & $\begin{array}{l}\text { Executive and } \\
\text { legislative directives } \\
\text { and reporting } \\
\text { requirements, act as } \\
\text { example, tenant } \\
\text { councils, user groups }\end{array}$ \\
\hline Operations & $\begin{array}{l}\text { Financial officers, } \\
\text { safety officers, } \\
\text { human resources } \\
\text { (HR), energy and } \\
\text { environmental } \\
\text { officers, } \\
\text { procurement } \\
\text { officers, IT staff, } \\
\text { security, travel, } \\
\text { public affairs, etc. }\end{array}$ & $\begin{array}{l}\text { Approve financial } \\
\text { plans, establish } \\
\text { policies for } \\
\text { procurement, } \\
\text { travel, security, IT, } \\
\text { HR, etc. }\end{array}$ & $\begin{array}{l}\text { Operate building } \\
\text { systems; purchase } \\
\text { energy; set policies } \\
\text { that affect energy } \\
\text { use (e.g., for travel, } \\
\text { commuting, } \\
\text { procurement, IT, } \\
\text { etc.) }\end{array}$ & $\begin{array}{l}\text { Management directives } \\
\text { for new operational } \\
\text { policies and } \\
\text { procedures, internal } \\
\text { suggestions for } \\
\text { improved policies, } \\
\text { feedback and } \\
\text { recognition for } \\
\text { exemplary work, targets } \\
\text { for energy reduction } \\
\text { goals }\end{array}$ \\
\hline Maintenance & $\begin{array}{l}\text { Building managers, } \\
\text { janitors, out- } \\
\text { sourced } \\
\text { maintenance } \\
\text { including heating, } \\
\text { ventilation, and air } \\
\text { conditioning } \\
\text { (HVAC), gardeners, } \\
\text { food service, etc. }\end{array}$ & $\begin{array}{l}\text { Maintain clean, } \\
\text { comfortable, and } \\
\text { secure workplace } \\
\text { environments; } \\
\text { collect trash, } \\
\text { recycling. }\end{array}$ & $\begin{array}{l}\text { Responses to } \\
\text { occupant requests } \\
\text { for comfort, timing } \\
\text { of maintenance } \\
\text { services (use } \\
\text { energy during or } \\
\text { outside of normal } \\
\text { operating hours) }\end{array}$ & $\begin{array}{l}\text { Management directives } \\
\text { for new maintenance } \\
\text { policies and } \\
\text { procedures, internal } \\
\text { suggestions for } \\
\text { improved policies, } \\
\text { feedback and } \\
\text { recognition for } \\
\text { exemplary work, targets } \\
\text { for energy reduction } \\
\text { goals }\end{array}$ \\
\hline Tenants (users) & $\begin{array}{l}\text { Workers, } \\
\text { managers, union } \\
\text { reps, others }\end{array}$ & $\begin{array}{l}\text { Fulfill mission } \\
\text { objectives, interact } \\
\text { with the immediate } \\
\text { work environment, } \\
\text { complain to } \\
\text { maintenance }\end{array}$ & $\begin{array}{l}\text { Immediate impact } \\
\text { on local appliances, } \\
\text { lighting, and } \\
\text { equipment; indirect } \\
\text { impact on HVAC } \\
\text { through building } \\
\text { operators }\end{array}$ & $\begin{array}{l}\text { Appeals to personal } \\
\text { conservation ethic; } \\
\text { competition towards } \\
\text { energy reduction goals, } \\
\text { feedback; recognition } \\
\text { and reward, etc. }\end{array}$ \\
\hline $\begin{array}{l}\text { Executive and } \\
\text { legislative } \\
\text { organizations }\end{array}$ & $\begin{array}{l}\text { Council on } \\
\text { Environmental } \\
\text { Quality, Office of } \\
\text { the Federal } \\
\text { Environmental } \\
\text { Executive, Office of } \\
\text { Management and } \\
\text { Budget, etc. }\end{array}$ & $\begin{array}{l}\text { Direct agencies on } \\
\text { energy/water/ } \\
\text { carbon goals, } \\
\text { determine } \\
\text { performance } \\
\text { metrics }\end{array}$ & $\begin{array}{l}\text { Enforcement, } \\
\text { reporting, } \\
\text { verification of } \\
\text { energy } \\
\text { consumption data }\end{array}$ & $\begin{array}{l}\text { Ratings, elections, } \\
\text { financial incentives, etc. }\end{array}$ \\
\hline
\end{tabular}




\subsection{Tools}

Tools are the means by which agencies conduct business and achieve their goals. Like rules, tools exist in the workplace and both allow and constrain current behavior practices. Tools encompass a range of artifacts, from timecards and desks to forms and coffeemakers to accounting procedures and spreadsheets for GHG calculation and reporting. An organization's tools support its standard operations and ensure consistency over the long term. Changes to institutional behavior must be supported by modified operational standards and tools. When an organization's tools are in opposition to change, the change is harder to achieve in the short term and endure in the long term. In the case of sustainability, a tool can be used to support, or enable, existing and new energy and resource efficient behaviors. Changes to tools that support sustainable behaviors include:

- Revised position descriptions and performance standards,

- Progress reports about strategic sustainability goals,

- Training on new strategies and best practices,

- New budget lines to highlight costs and savings or to support initiatives.

Tools can be linked through a process of measuring, aggregating and reporting. The institutional and behavioral principles provide guidance as to potential points of intervention and (possibly) specific means for altering existing tools or creating new ones. Because of their importance in the EO and its associated SSPPs, we discuss accounting, reporting, and compliance tools separately, below.

\subsubsection{Accounting, reporting, and compliance}

As described in section 3.0, the EO establishes quantitative and non-quantitative goals for federal agencies. To assist agencies in meeting the reporting requirements, guidance and tools have been developed by FEMP and the Council on Environmental Quality (CEQ), and made available through various documents and software. Two key documents for accounting and reporting are the CEQ Guidance ${ }^{4}$ and the CEQ Technical Support Document ${ }^{5}$. The former provides more definition of requirements, while the latter provides detailed information on types of information to be collected and aggregated, and various methodologies to conduct the analysis. All reporting by agencies is done through the FEMP Reporting Portal ${ }^{6}$.

The CEQ Guidance document makes the important point that reporting and reduction are separate, discrete tasks. From the standpoint of institutional-behavioral interventions, it is important to have a well-defined model of the activities contributing to GHG emissions, so that the best reduction methods can be developed, and implemented.

A principal tool for developing reports is the FEMP Annual GHG Sustainability Data Report, Version $1^{7}$. Other calculation tools are available via the FEMP website, which includes links to tools provided by the GHG Protocol Initiative ${ }^{8}$. As stated in the CEQ Technical Support Document, final reporting is accomplished through the FEMP Reporting Portal, but agencies may use other tools available to them to facilitate the process. Agencies are cautioned to ensure that any specific tools they employ are properly aligned with the Technical Support Document.

\footnotetext{
${ }^{4}$ http://www.whitehouse.gov/sites/default/files/microsites/ceq/GHG\%20Guidance\%20Document_0.pdf

${ }^{5} \mathrm{http}: / /$ www.whitehouse.gov/sites/default/files/microsites/ceq/Technical\%20Support\%20Document_0.pdf

${ }^{6} \mathrm{http}: / /$ www.fedcenter.gov/_kd/go.cfm?destination=Page\&pge_id=3788

${ }^{7} \mathrm{http}: / /$ www1.eere.energy.gov/femp/docs/ghg_datareport_v1-1_20101008.xlsx

${ }^{8} \mathrm{http}$ ://www.ghgprotocol.org/calculation-tools/all-tools
} 
(THIS PAGE LEFT BLANK INTENTIONALLY) 


\section{EVIDENCE-BASED PRINCIPLES TO GUIDE THE SELECTION OF STRATEGIES FOR INITIATING AND MAINTAINING INSTITUTIONAL CHANGE}

In designing strategies to effect organizational change that increasingly values sustainability, research results provide insights into individual and organizational behavior that can lead to effective implementation. We have derived the eight principles from the literature. These principles are summarized, below, and then described in more detail. These more detailed descriptions suggest ways to implement the principle, followed by related evidence.

1. The Social Network and Communications Principle:

Institutions and people change because they see or hear of others (individuals, groups, institutions, firms, etc.) behaving differently.

2. The Multiple Motivations Principle:

Institutions and people almost always change their ways of doing things for more than one reason.

3. The Leadership Principle:

Institutions and people change because the workplace rules change and visible leadership communicates management commitment.

4. The Commitment Principle:

Institutions and people change when they have made definite commitments to change, especially when those commitments relate to future conditions (such as making arrangements to "save more tomorrow").

5. The Information and Feedback Principle:

Institutions and people change because they receive actionable information and feedback.

6. The Infrastructure Principle:

Institutions and people change because a changed infrastructure makes new behaviors easy and/or desirable.

7. The Social Empowerment Principle:

Institutions and people who feel they can reach desirable social goals-often do.

8. The Continuous Change Principle:

Institutional change takes time.

\subsection{The Social Network and Communications Principle}

Institutions and people change because they see or hear of others (individuals, groups, institutions, firms, etc.) behaving differently, so make sure staff see or hear about others who have changed their office settings or patterns of behavior.

\subsubsection{Description}

Both individuals and institutions are social beings - that is, we behave in ways that are deeply, sometimes unconsciously, influenced by the expectations and actions of others. Moreover and specifically, when conditions change, we take notice of what others are doing and often are led to 
similar actions. Howard Kunreuther (1978) found that the only reliable predictor of whether one farmer would buy flood insurance was whether that farmer knew someone else who had such insurance. Social network researchers have found that you can lose weight or quit smoking if someone even two or three degrees separated from you (i.e., whom you don't know) accomplishes these goals. The "social contagion" of fads in fashion and consumer goods (popularized in The Tipping Point by Malcolm Gladwell 2000) demonstrates this tendency of individuals, but the same tendency has been observed in organizations, who tend to structure themselves in the same ways and have similar "corporate trappings" such as visions and missions, and even in countries, who show isomorphism in significant ways (Meyer 1999). In its institutional dimensions, this principle describes both behavioral and cultural change; people are bringing their values, beliefs, and actions into line with those of others (Stephenson et al. 2010).

\subsubsection{Practical advice for program design and implementation}

The implications of this principle for sustainability programs are that programs will be much more effective if they make visible throughout the institution that other institutions and people have adopted sustainability-relevant behaviors. Heath and Heath (2010, p. 228) go so far as to say that "if you want to change things, you have to pay close attention to social signals, because they can either guarantee a change effort or doom it." Specific actions include involving staff in the discussion of proposed changes, introducing changes in informal meetings (don't forget the bagels or cookies!), ensure that managers and leaders model desired behaviors (see the Leadership Principle) and continuing to relay stories about others' successes.

\subsubsection{Examples from the literature that support this principle}

Griskevicius et al. 2008, cited in Ehrhardt-Martinez and Laitner 2010: When a situation changes and people don't know what to do, they “... don't look inside themselves for answers .. instead they look to others for evidence of how to act. This means that when conditions have recently changed - because of an introduction of a new green product, a new report, or a new law related to pro-environmental action - the unfamiliar conditions will make people especially attentive and responsive to information about how others are dealing with it."

Cialdini 2005: For a study of hotel guest behavior, researchers left cards in each room asking guests to reuse their towels and noting that the majority of people staying in the hotel had, at some point in their stay, reused their towels. Reuse rates rose from 35\% to 58\%. Making the advice as specific to the situation as possible improves effectiveness.

Schultz et al. 2007: Revealing social norms changes energy consumption patterns: Notices were left on household doorsteps, indicating how energy consumption in that house compared to the neighborhood average. Homeowners consuming more electricity than their neighbors reduced their consumption.

Social Networking distributes 2.5 million CFLs: Project Porchlight (run by One Change, a nonprofit organization in Ottawa) uses social networks to distribute compact fluorescent light bulbs (CFLs) and encourage households to change their behaviors. With projects in Canada and the United States, the organization now and has distributed more than 2.5 million CFLs. Evaluations suggest that $70 \%$ of the CFLs are installed immediately, and recipients are more likely to buy other energy efficient appliances. 
Social Outreach Catalyzes 19\% Reduction in Household Energy Consumption: 20/20 The Way for Clean Air in Canada catalyzed a 19\% reduction in household energy consumption and a 15\% reduction in vehicle miles traveled per household between its inception in 2002 and 2004. The program relied on social marketing techniques, information dissemination, and other means.

Focus the Nation (cited in Ehrhardt-Martinez and Laitner 2008): Both new and established networks of people who actively seek to change individual behavior can challenge existing social norms and/or social structures. Focus the Nation mobilized nearly one million people at more than 1900 events, where students and other citizens learned more about climate change issues and also challenged participants to begin to take action. (More information is available at www.focusthenation.org.)

Gershon 2009. Social Change 2.0: Gershon initiated and tested a community-based environmental behavior-change program called Low Carbon Diet beginning in 2006. The program consisted of 24 steps to reduce personal carbon footprints by at least 5,000 pounds in 30 days and to help others do the same. Low Carbon Diet grew out of Gershon's experience working with 20,000 people organized into neighborhood-based peer-support groups-EcoTeams — who reduced their environmental footprint $25 \%$ in cities ranging from the environmentally progressive Portland (OR), and Madison (WI), to the more middle-of-the-road Columbus (OH), Kansas City (MO), and Philadelphia (PA). The effort was scaled up, and as of 2009 over $300 \mathrm{Cool}$ Communities exist in 36 U.S. states. Participants are achieving on average a $25 \%$ carbon footprint reduction and reaching out to fellow citizens to accomplish the same. One key was commitment by local governments, faith-based groups, and environmental groups. Another is that a Cool Community also enables a city or town to enjoy the immediate practical benefits of more livable neighborhoods, greater environmental sustainability, and economic development. Furthermore, it creates a robust long-term carbon reduction capability by building the community leadership, carbon-literate citizenry, and political will necessary to sustain this type of change over time. http://www.huffingtonpost.com/david-gershon/hope-for-a-climate-change_b_401298.html

Cialdini 2010: Cialdini points out that it's a mistake to represent a problem as many people misbehaving, because the message the audience gets is that many people are engaging in the behavior; thus, the behavior is legitimized. Instead, the desired behavior should be represented as "widely performed and roundly approved" and the undesired behavior as rare and disapproved.

Centola 2010: A study of social networks concluded that network ties that are locally clustered spread behaviors faster because people receive information and reinforcement from multiple neighbors, friends, and colleagues.

Harris et al. 2010: Social marketing strategies seek to develop the sense that "everyone" is being energy efficient. Engaging social networks can take the form of Home Energy Efficiency Teams, neighborhood canvassing with small giveaways, and sharing tips by Facebook "fans" of ConEd's Power of Green.

Martinez and Geltz 2005: Change messages must contain information and incentives and personal contacts, preferably from people who are in the same category (e.g., business owners). 


\subsection{The Multiple Motivations Principle}

Institutions and people almost always change their ways of doing things for more than one reason, so make different and combined appeals.

\subsubsection{Description}

As a standalone set, sustainability goals probably won't get much traction; they will be seen as another unfunded mandate or "other duties as assigned" - unless there are other benefits to be gained along with meeting the sustainability goals. One benefit for groups and individuals might be that sustainability goals are extensions of or consonant with efforts they're already making, like buying fair trade coffee and Energy Star computers and appliances, seeking LEED certification for their new building, or riding bicycles to work. Other appeals that, alone or in combination, have been found to motivate people include the wish to "do the right thing," increase comfort, set a good example for children, be cool/trendy, help the country innovate, work together on a project, even save money. However, people don't buy efficient stoves, hybrid cars, or low-carbon-input food because these things are cheap. People choose to buy these products because they're cool, fit a lifestyle, have features that appeal - and to be like others they know who have such products (a number-one reason for many purchases - see the Social Networks and Communication Principle).

\subsubsection{Practical advice for program design and implementation}

Ask people — staff at all levels — why they might get involved in sustainability activities. When they identify other benefits, whether synergies or tradeoffs, incorporate these into program design and communications. Design appeals that relate to comfort, convenience, special features (such as dashboard-type information) outside of energy efficiency, exercise programs, trendiness, setting a good example, or just "doing the right thing." Repeat these motivational appeals, preferably in combination.

\subsubsection{Examples from the literature that support this principle}

McMakin et al. 2002: In a successful project to reduce energy use in military housing (i.e., without economic incentives - these inhabitants don't pay utility bills), what participants said was that they wanted to (1) do the right thing, (2) set an example for their children, (3) show that theirs was the best military service, and (4) have comfortable homes.

Weber and Lindemann 2007: Decisions get made in qualitatively different ways: (1) "by the head" - calculation-based decisions, (2) "by the heart" - emotion-based decisions, and (3) "by the book"-rule-based decisions.

Heffner et al. 2006: Analysts have pointed out that the value proposition of hybrid electric vehicles (HEVs) is questionable, since the payback period is so long. In fact, many owners will not recover their investment. However, HEV owners have different motivations; they receive symbolic meaning and value from owning such vehicles. 
Larson 2009: Pacific Gas and Electric's More than a Million Program directly targets large customers with multi-facility portfolios or "fleets" of buildings to participate in energy efficiency projects. The approach involves multiple means of assessment and implementation, and multiple customer and utility benefits. The approach establishes a team environment by bringing in all vested interests to develop plans and targets. In one successful initiative, a large financial institution implemented efficiency initiatives at 270 sites and reported fleet average energy savings per square foot of $3.7 \%$ compared to the baseline year.

Schein 1999: Culture, defined as "a pattern of shared basic assumptions that the group learned as it solved its problems of external and internal integration, that has worked well enough to be considered valid and, therefore, to be taught to new members as the correct way to perceive, think, and feel in those problems," can be change-resistant or change-oriented. In the former case, it will be important to demonstrate that the desired changes reinforce existing assumptions about the ways to act.

Information feedback and energy behavior 2010: The Center for the Built Environment at the University of California, Berkeley, conducted a survey, in part to ask users about their motivations. The three top motivations were: to benefit the environment; "because it is the right thing to do" and to save money for the company.

Grim 2006: Beyond saving energy and costs, this article points to other motivations for installing energy-efficient conditions: the need to upgrade and modernize buildings, lack of comfort in the workplace spaces, rising energy prices, and improvement of safety.

\subsection{The Leadership Principle}

Institutions and people change because the workplace rules change and visible leadership communicates management commitment, so be visible and demonstrate commitment.

\subsubsection{Description}

Active leadership, from both managers and other staff members, sends workplace groups the signal that sustainability is something they need to pay attention to, rather than shrugging off what could be seen as a diversion from the "real" work of the agency. Beyond merely "approving" the effort, a high-level, well-respected individual should personally champion sustainability. The involvement of a high-ranking person demonstrates the importance of the effort, as well as a top-down commitment. If written or public commitments are asked for, leaders should be among the first to make such commitments (see the Commitment Principle).

\subsubsection{Practical advice for program design and implementation}

Demonstrate by showing up and following up that the agency and your workplace are serious about making sustainability an important goal. First-line supervisors at every level need to be brought on-board and given the motivation and tools (technical assistance, funding, analysis time) to address identified issues (Giardini, Giuliani, and Marricchi, 2011). 


\subsubsection{Examples from the literature that support this principle}

Kotter 1996: For conditions of change, a leader must be able to establish a sense of urgency or importance and to develop and communicate a vision for change. Such leaders should also have a good understanding of the politics of the organization, be able to tie the change agenda to the underlying culture, create a dominant coalition within the organization in support of change, motivate support by empowering employees, and generate short-term wins.

Cameron and Quinn 1999: Many of the most successful companies, including Southwest Airlines, Wal-Mart, Tyson Food, and Plenum Publishing have strong leadership that promotes unique strategies and a strong culture to help them realize the strategies.

Giardini et al. 2011: By using bank branch managers as the focal point for a change program, a large European bank was able to reach 30,000 local branch employees and 2,000 senior managers through staff with sufficient local credibility to influence change, but also enough seniority to communicate with upper management. This approach was used as an alternative to a "top-down" change process, which had little impact on day-to-day operations.

\subsection{The Commitment Principle}

Institutions and people change when they have made definite commitments to change, especially when those commitments relate to future conditions (such as making arrangements to "save more tomorrow"), so ask for specific commitments.

\subsubsection{Description}

People who make commitments to do something tend to have higher rates of follow-through and success than people who don't, regardless of their favorable attitudes. This is a widespread finding of social science research. In weight-loss advice, a common recommendation is to tell your friends you are going on a diet; this helps you externalize your internal goals and increases the likelihood that you will realize them. For energy efficient behaviors, numerous studies have demonstrated this principle. Ariely (2009) notes that, without pre-commitments, people tend to procrastinate.

\subsubsection{Practical advice for program design and implementation}

At staff meetings where sustainability goals and activities are discussed, hand out cards with wording that both ties into the workplace culture and invites the staff members to define their own behavioral changes or goals. An example for a workplace where teamwork is valued and peer relationships are strong could be, "With my co-workers, I will adopt the following practices:" followed by several blank lines. Potential shared goals should be discussed in the meeting. For new staff members, the on-boarding paperwork could include a statement to the effect that the office is committed to becoming more sustainable (along with specific goals as applicable) and ask the new employee to sign ("as almost all of current staff have"), signifying that he or she will join the effort. 


\subsubsection{Examples from the literature that support this principle}

Becker 1978 and Pallak et al. 1980: These studies of residential energy consumption asked homeowners to commit to lowering energy consumption. Becker's study found that individuals who committed to a goal of a $20 \%$ reduction (over a three-week period) reduced consumption by $15 \%$ with the aid of regular feedback. Participants who committed to goals of only $2 \%$ reduction did not achieve any reduction in energy use. The Pallak et al. study also looked at the effect of public versus private commitments on energy conservation. Not surprisingly, individuals who made public commitments used significantly less electricity and natural gas than both control subjects and those individuals that made private commitments.

McKenzie-Mohr and Smith 1999: Partnering with a California utility, home assessors were trained to make use of commitment strategies. The assessors then sought verbal commitments from householders. For example, an assessor might ask the homeowner when he or she anticipates having a weather stripping project completed and suggest a call around that time to assess progress and/or offer help. By changing the way in which the assessment was presented, the use of commitment and related techniques resulted in three to four times as many people retrofitting their homes.

Gershon 2009 Social Change 2.0: Currently over 300 Cool Communities exist in 36 U.S. states (see more detail under the Social Network and Communications Principle, above). Participants are achieving on average a $25 \%$ carbon footprint reduction and reaching out to fellow citizens to accomplish the same. One key was commitment by local governments, faith-based groups, and environmental groups.

Thaler and Sunstein 2008: People have a tendency to procrastinate, to take early gratification over distant benefits. One way to counter this tendency is a choice architecture called "save more tomorrow," in which people sign up to increase their savings rates every time they get raises. A parallel might be to institute energy savings with each change in the relevant building infrastructure or change in seasons or change in other circumstances sometime in the future.

Broc et al. 2006: The campaign described, which achieved 10\% energy savings, was based on "commitment theory" from experimental social psychology. If people make voluntary commitments to engage in "insignificant" actions at first, then, when they see successful results, they will be willing to take on more difficult commitments.

Flahaut et al. 2001: This study demonstrated "commitment theory" with homeowners. People who committed to take seemingly insignificant actions, such as turning off unnecessary lights at night, on a systematic basis, will not only develop more positive attitudes toward energy efficiency but also will be more willing to undertake more costly actions, such as buying efficient light bulbs.

\subsection{The Information and Feedback Principle}

Institutions and people change because they receive actionable information and feedback, so provide tools and resources tailored to specific workplace situations. 


\subsubsection{Description}

Comparison and even competition are powerful motivators, as shown in several current programs that provide real-time feedback (on the internet) or comparisons on utility bills. These programs lower energy use. "Actionable information" means the opposite of the usual laundry lists of actions, untailored to any specific situation; instead, items must be implementable in the actual workplaces where they are suggested. That is, people must be able to see themselves taking those actions; if not, the result will be discouragement at best, tuning out of the whole program at worst.

\subsubsection{Practical advice for program design and implementation}

Energy use and savings should be made visible, thus providing goals and motives where they did not previously exist. Calculating facility, group, or individual carbon footprints can be engaging, empowering (see the Social Empowerment Principle), and effective. If local meters can be installed, reporting the usage data at frequent intervals will likely result in lower energy use if those receiving the feedback are able to take effective action in response. Other actionable information should include only those activities that can be implemented in the specific situations of workplaces.

\subsubsection{Examples from the literature that support this principle}

Owen et al. 2010: This paper illustrates how employee engagement measures, coupled with an energy information system, achieved electricity savings of $12 \%$ in the Jack Davis Building, Victoria, BC, Canada, over and above the impact of installing new energy efficiency technologies. This savings was achieved by 5 th floor staff during a one-week campaign. The success of the campaign may have been influenced by the extensive community-based social marketing (CBSM) efforts of the Green Team and Strategic Energy Manager during the year before. The results highlighted an important relationship between prompts and feedback - that information on its own may be insufficient to facilitate persistent action.

Thaler and Sunstein 2008: New "mental accounts" provide new goals; examples are personal carbon footprint accounts and dashboard displays on hybrid vehicles.

Loewenstein and Prelec 1992: Households tend to use different mental accounting systems for different kinds of expenditures; recurring expenses (gas and electricity) are different from appliance purchases, which in turn are different from financial investments. As a result, households tend to be relatively insensitive to information about expected returns on investment in energy efficiency.

Thaler and Sunstein 2008: Policies and programs should design environments and structure choices to encourage people to make better choices. For example, the default option should be set with the best interest of the chooser in mind. When healthy food choices are placed at the beginning of a school cafeteria line, students are much more likely to choose the healthier foods.

Winkler and Winett 1982: In 19 sets of data from experimental studies, households were informed frequently (usually daily) about how much energy they were using. The feedback made energy more visible to participants who modified their habits and reduced their energy consumption by 
as much as $20 \%$. The authors also found that the feedback was even more effective when energy prices were higher.

Hammerstrom et al. 2007: Advanced technologies allow consumers to trade flexibility for lower costs, giving providers the demand information they need to determine the actual cost of generation, transmission and distribution in near-real time. The study found that participants reduced their energy consumption simply because their energy use was more visible and because they had greater control over their energy consumption decisions.

Laskey 2009: Through innovative Home Energy Reports, homeowners have reduced household energy consumption by $2.4 \%$. OPower's program uses a combination of effective norm-based messaging and tailored recommendations to motivate people to take action and reduce their consumption. OPower combines a variety of different publicly available data sources with utility data to gain insights about housing characteristics, demographics, weather, and energy use. The company uses this information to develop monthly reports that provide consumers with information about their unique use patterns and how their consumption patterns compare to their neighbors. As a result, consumers can assess where their consumption practices lie within the larger spectrum of energy users. In addition, demographic data and household characteristics are used to develop specific recommendations about ways in which consumers can reduce their consumption. As Laskey suggests, $60 \%$ of report recipients report making home or lifestyle changes and ongoing evaluations indicate that energy savings are persistent over time.

Darby 2006: Darby reviewed 38 studies of energy-efficiency and found that feedback reduced energy usage by $10-14 \%$ on average.

Komor et al. 1989: Interview research showed that feedback is much more effective when matched to the user's area of responsibility - annual or monthly data for contractors and others selecting equipment, shorter-term data for building operators. Feedback should include both dollars and energy units - dollars are more readily understood, and energy units allow controlling for rate changes.

\subsection{The Infrastructure Principle}

Institutions and people change because a changed infrastructure makes new behaviors easy and/or desirable, so change defaults (indoor temperature, printer settings, walkability of halls and stairwells, provision or no provision for parking, etc.) and provide motivations as well as incentives to use infrastructure differently (e.g., special status/benefits for van pool and public transportation users).

\subsubsection{Description}

How building space is configured and how choices are presented make huge differences in the choices people make. Sustainability can be promoted through good choice architecture (Thaler and Sunstein 2008). Some examples bring home the point. When a vegetarian option is presented first for a conference meal (as in the November 2009 Behavior, Energy, and Climate Change conference), many more people choose it. When a company provides benefits for public transport but not for parking, more people use public transportation. The "defaults" of the physical environment can also either promote or present a barrier to energy-saving behavior. For example, 
characteristics of the built environment (e.g., whether a city is walkable) and technology (e.g., whether programmable thermostats are intuitive to use) can have a significant effect on behavior (Armel 2008). Moezzi (2009) discusses an interactive process of "adaptive comfort." For example, building managers can widen the designed temperature acceptability range and give occupants leeway to adapt. Advantages accrue in lower energy demand, higher staff satisfaction, and ease of operation (buildings/people are complicated enough that attempts to narrowly control temperature may often work poorly anyway). In the area of new equipment choices, when the Danish government persuaded its window manufacturers to present low-e windows first in their marketing materials, sales of low-e windows shot up. This example illustrates the importance of anticipating the effect of "upstream" decisions on consumer choice, and the ultimate impact on energy savings.

\subsubsection{Practical advice for program design and implementation}

Change the default settings for the heating and air conditioning system-but be sure to consult staff and readjust as necessary. If possible, allow staff to adjust settings, which often leads to lower energy use and empowers staff. Identify, with staff input, what features of a work-at-home program, carpooling or public transport incentives would facilitate adoption.

\subsubsection{Examples from the literature that support this principle}

Winner 1982, cited in Sovacool 2009: "Americans have shifted from a value system premised on self-restraint and moderation to the idea that freedom and social well-being are best achieved through sheer abundance and limitless consumption" (p. 4509). These values, far from floating "out there" in the minds of people, become a powerful and socializing force built into the physical environment and the energy system.

Newman and Day 1975, cited in Sovacool 2009: A two-year study involving a national survey of 1500 households and 125 public utilities found that all households have circumscribed choices concerning the energy-related features of their homes. The architectural design, selection of appliances, and structure of built-in equipment are already there. Central heating and cooling systems allow people to move freely from one room to another without thinking about energy, but remove the option of saving fuel by closing off unused rooms. Architects design apartment and office buildings with windows that cannot open for safety, but make it impossible to rely on natural heating and cooling.

Tienda and Aborampah 1981, cited in Sovacool 2009: Many households in Wisconsin did not cope well with the energy crises of the 1970s. The physical and structural characteristics of their homes and vehicles diminished their ability to purchase more efficient automobiles and appliances or undertake retrofits. The authors concluded that these "built in" factors are more important than any other socioeconomic indicator, such as family size, gender, or personal values, in molding patterns of electricity and energy consumption.

van Nieuw-Amerongen et al. 2009. Interventions, including prompts and enhanced aesthetics, visibility, and accessibility of the stairwell, resulted in an $8.2 \%$ increase in total stair use. Effects remained stable over the 4-week post-intervention period. Stair use can be positively and continuously influenced by improving the stairwell environment. 
McKenzie-Mohr and Smith 1999. Two groups of homeowners received a pamphlet on energy conservation. For one group a shower flow restrictor accompanied the pamphlet; the other group only received the pamphlet. The researchers found that homeowners who received the shower flow restrictor were more likely to engage in the other conservation actions mentioned in the pamphlet (i.e. reducing the temperature on their hot water heaters, installing setback thermostats and cleaning their furnaces). The study concludes that the householders' perceptions of themselves were changed by installing the shower flow restrictor, and they were more likely to view themselves as concerned about energy conservation.

Stern 2009: Considering only rates of program participation, the recent Cash-for-Clunkers program was much more effectively designed than the Residential Energy Efficiency Tax Credit. Cash-for-Clunkers and other successful programs have (1) gotten vendors to do the marketing, (2) taken the consumer's standpoint and minimized hoops, (3) developed credible information about savings, (4) provided information on the effects after the fact, and (5) rated service providers and inspections of work.

\subsection{The Social Empowerment Principle}

Institutions and people who feel they can reach desirable social goals often do, so involve people in program design and processes.

\subsubsection{Description}

Daniel Pink, in Drive, draws on various well-established social science research to show that workers are not motivated by sticks and carrots but by three desires: autonomy, (people want to have control over their work), mastery (people want to get better at what they do), and purpose (people want to be part of something that is bigger than they are). Appealing to these motivations will be far more effective than putting in place rules and sanctions and/or prizes for the best sustainability performance.

\subsubsection{Practical advice for program design and implementation}

Involve appropriate staff as much as possible from the early stages of program design to full implementation. This action would mean engaging early - and continuously-people in leadership positions as well as those most familiar with operational elements that need to be changed or that would be affected.

\subsubsection{Examples from the literature that support this principle}

"Information feedback" 2010: A survey conducted by the Center for the Built Environment (170 office workers) identified the primary motivation for eco-friendly behavior to be the need to benefit the environment and "do the right thing" as well as to save money for the company-all can be categorized as being part of something bigger. 
WBCSD2010: The World Business Council for Sustainable Development points out the importance of developing the capacity of facilities engineers and maintenance workers to achieve energy efficiency, but they need knowledge, tools, and authority to act.

Harris et al. 2010: Social marketing targets specific groups and people, suggesting a few behaviors rather than many, so people can be empowered to change and to become change agents.

\subsection{The Continuous Change Principle}

Institutional change takes time, so plan for the multi-year process.

\subsubsection{Description}

The organizational change literature emphasizes that change management efforts often fail because the change is not sustained. The key to achieving and sustaining significant change is altering the basic ways of thinking within the organization, but this is difficult to achieve and sustain (Senge et al. 1999). Kotter (1998) recommends allowing ten years of effort to accomplish major transformative changes; while a shift to sustainability values and practices might not rise to the "major transformative" level, it must be considered a multi-year process.

\subsubsection{Practical advice for program design and implementation}

Plan from the beginning for the longer term, with activities that can be implemented now and others that are planned for the coming years (facility upgrades, for instance). Follow kick-off events with regular messages about goals and activities. Include sustainability in new employee orientations. Ask staff at regular intervals what they are doing and what management could do to increase sustainability. The principal message here is that sustainability program design and implementation is a continuous process, which should be incorporated into ongoing business practices.

\subsubsection{Examples from the literature that support this principle}

Smith 2005: Smith distinguishes between the objectives of raising awareness and changing behavior and between the tools appropriate to accomplish each. For raising awareness, positivist techniques may work: providing information, incentives, and disincentives. They may not actually change behavior, however. "Some people will not listen to or read the materials given to them, some do not care about the incentives and others may simply ignore the law when it is not being adequately enforced. They may resent being manipulated and coerced by the government and resist changing" (Smith 2005: 3). To effect change, people need to feel that the new behaviors are important, worthwhile, and achievable. They should be encouraged to make small changes first and build on successes. Managers should change the environment or context or infrastructure to make changing easy-easier than continuing old behaviors. They need to problem-solve with staff and do their part to remove barriers, change policies and procedures, etc. Finally, Smith points out that asking people to do something they cannot do makes the situation worse. 
Darby 2006: Several studies, reported here, show that the length of the pilot or trial period influences the length of the change. At the conclusion of one three-year study, people could no longer identify the changes they had made, so ingrained had the changes become. 


\section{NEXT STEPS}

Because sustainability is an inherently integrated concept, the strategies used to achieve sustainability also must be integrated. People are central to achieving sustainability goals associated with changes in technologies, systems, policies, and procedures - and to maintaining or improving upon those achievements over time. Institutional change embodies a changing the way business is done approach, which is distinct from one that centers on compliance with EO 13514 reporting requirements. An institutional culture in which sustainability is fully integrated can meet and improve upon its energy saving, GHG, and resource use goals - even in the face of staff turnover or inevitable organizational and technological changes. This document provides the conceptual and evidentiary foundations for initiating and maintaining this kind of institutional change.

We have sketched an action-oriented institutional change process whose five steps are key to a cycle of continuous improvement: set sustainability goal, assess institutional context, design action plan, implement plan, measure and evaluate. We emphasized crucial components of institutional context, namely rules, roles, and tools. In addition, we described eight evidencebased principles that apply when developing and implementing strategies to effect change.

Our overarching goal is to provide guidance to federal agencies as they work to achieve and maintain sustainability goals while continuing to meet their mission needs. This guidance, which we have begun to provide, takes many forms - training, workshops, direct technical assistance, a website, presentations, publications, etc. Our next steps are to continue to translate information into actionable guidance in all of these venues. At the same time, particularly because there are many gaps and inconsistencies in existing literature, we are using our interactions with federal agencies as sources of information. The information we gather through interactions with agencies is useful in at least two ways. First, we continually learn about real-world problems and dynamics in moving toward sustainability in federal agencies, and about cases in which some success has been achieved. This information expands the evidentiary base that we and others can use. Second, interactions with agencies help us identify what guidance is needed and how best to provide it. Beyond our team and this institutional change effort, there is a considerable need for research and evaluation specific to institutional (versus individual) change, workplace settings, and energy savings, GHG reductions, and sustainability. There is little substantive research at the convergence of these elements. In an endeavor as complex as changing institutional behavior to achieve sustainability goals that has so much potential consequence, both an evidentiary base and progress are needed. 


\section{REFERENCES}

Anfara, V.A. (2008). Theoretical Frameworks. In L. Given (Ed.). The Sage Encyclopedia of Qualitative Research Methods. Thousand Oaks, CA: Sage Publications. Volume 2, pp. 869-873.

Ariely, Dan 2009. Predictably Irrational: the Hidden Forces that Shape Our Decisions. Harper, New York.

Armel, Carrie. 2008. Energy, behavior, and design. Presentation. October 28. Precourt Institute for Energy Efficiency and Stanford University.

Becker, L. 1978. "The Joint Effect of Feedback and Goal Setting on Performance: A Field Study of Residential Energy Consumption.” Journal of Applied Psychology 63:428-433.

Broc, Jean-Sébastien, Bertrand Combes, Sandrine Hartmann, Bernard Bourges, Marie-Isabelle Fernandez and Jérôme Adnot 2006. Raising awareness for energy efficiency in the service sector: learning from success stories to disseminate good practices. In Improving Energy Efficiency in Commercial Buildings. Frankfurt am Main, Germany.

Cameron, Kim S. and Robert E. Quinn 1999. Diagnosing and Changing Organizational Culture: Based on the Competing Values Framework. Addison-Wesley, Reading, MA.

Centola, Damon 2010. The spread of behavior in an online social network experiment. Science 329 (3 September): 1194-1197.

CEQ. (2010). Federal Greenhouse Gas Accounting and Reporting Guidance. http://www.whitehouse.gov/sites/default/files/microsites/ceq/GHG\%20Guidance\%20Document_ $0 . p d f$

Cialdini, R.B. 2010. Influencing change: applying behavioral science research insights to reframe environmental policy and programs. Presented to the 2010 Behavior, Energy and Climate Change Conference. CITY

Cialdini, R.B. 2005. Basic social influence is underestimated. Psychological Inquiry 16(4), 158161.

Darby, Sarah. 2006. "The Effectiveness of Feedback on Energy Consumption: A review for DEFRA of the literature on metering, billing and direct displays." Oxford, England:

Environmental Change Institute, University of Oxford.

Dietz, Thomas; Gardner, Gerald T.; Gilligan, Jonathan; Stern, Paul C. And Michael P. Vandenbergh. 2009. Household actions can provide a behavioral wedge to rapidly reduce United States carbon emissions. Proceedings of the National Academy of Sciences of the United States of America. Washington, DC: National Academy of Sciences.

Douglas, Mary. 1986. How institutions think. Syracuse University Press, Syracuse, NY.

Ehrhardt-Martinez, Karen and John A. "Skip" Laitner. 2008. Behavior, Energy, and Climate Change: Emerging Policy Directions, Program Innovations, and Research Paths. Report Number E087. American Council for an Energy-Efficient Economy. 
Ehrhardt-Martinez, Karen and John A. "Skip" Laitner. 2010. Buildings, Energy Efficiency and People: Integrating People-Centered Insights and Initiatives to

Accelerate and Deepen Energy Savings. Report to the U.S. Department of Energy and Argonne National Laboratory, September, Washington, DC.

Flahaut, Dominique, Jean-Michel Graillat, Jean-Léon Beauvais and Robert-Vincent Joule. 2001. Energy savings using the commitment theory, ECEEE 2001 Summer Study, panel 2, 342-351. Mandelieu, France.

Gardner, Gerald T. and Paul Stern. 2008. The short list: The most effective actions U.S. households can take to curb climate change. www.environmentmagazine.org 50(5): 13-24.

Garud, Raghu and Peter Karnøe (eds). 2001. Path dependence and creation. Lawrence Erlbaum Associates, Mahwah, NJ, and London.

Gershon, David 2009. Social Change 2.0: A Blueprint for Reinventing the World. High Point.

Giardini, M., Giuliani, G., and Marricchi, M. 2011. Finding the right place to start change. McKinsey Quarterly, McKinsey and Company, November.

Giddens, Anthony. 1986. Sociology: a brief but critical introduction. Macmillan, London.

Gladwell, Malcolm 2000. The Tipping Point: How Little Things Can Make a Big Difference.

Little Brown, New York.

Grim, Margot 2006. The Austrian programme for private service facilities: ecofacility. In Proceedings for the $4^{\text {th }}$ International Conference for Improving Energy Efficiency in Commercial Buildings - IEECB'06. Office for Official Publication of the European Communities,

Luxembourg.

Hammerstrom D.J., J. Brous, D.P. Chassin, G.R. Horst, R. Kajfasz, P. Michie, T.V. Oliver, T.A. Carlon, C. Eustis, O.M. Jarvegren, W. Marek, R.L. Munson, and R.G. Pratt. 2007. Pacific Northwest GridWise ${ }^{\mathrm{TM}}$ Testbed Demonstration Projects; Part II. Grid Friendly ${ }^{\mathrm{TM}}$ Appliance Project. PNNL-17079. Richland, Wash.: Pacific Northwest National Laboratory.

Harris, J., J. Hummer, and P. Thompson. 2010. Behavior Change Interventions; What Works, What Doesn't and Why. ACEEE Summer Study on Energy Efficiency in Buildings.

Heath, C. and D. Heath. 2010. Switch: How to Change Things When Change is Hard. Broadway, New York.

Heffner, Reid R., Thomas S. Turrentine, and Kenneth S. Kurani. 2006. "A Primer on Automobile Semiotics.” Davis, Calif.: Institute of Transportation Studies, University of California.

Information feedback and energy behavior 2010. In "Behavior and Buildings," the newsletter of the Center for the Built Environment at the University of California, Berkeley. Summer. www.cbe.berkeley.edu

International Atomic Energy Agency. (2002). Safety culture in nuclear installations: Guidance for use in the enhancement of safety culture. IAEA-TECDOC-1329. 
Komor, Paul, Willett Kempton and Jeff Haberl 1989. Energy Use, Information, and Behavior in Small Commercial Buildings. PU/CEES Report 240. Princeton University, Princeton, NJ.

Kotter, John 1996. Leading Change. Harvard Business School Press, Boston.

Kotter, John P. 1998. Leading change: why transformation efforts fail. In Harvard Business Review on Change. Harvard Business School Press, Boston.

Kunreuther, H., R. Ginsberg, L. Miller, P. Sagi, P. Slovic, B. Borkan and N. Katz. 1978. Disaster Insurance Protection: Public Policy Lessons. New York, John Wiley.

Laitner, Skip; Ehrhardt-Martinez, Karen and Vanessa McKinney. 2009. "Examining the Scale of Behavior Energy Efficiency Continuum." Prepared for the 2009 ECEEE Summer Study on Energy Efficiency.

Larson, Duane 2009. More than a Million Program, Pacific Gas and Electric. Presented to the DOE Energy and Behavior Workshop, October 6, Washington, DC.

Laskey, Alex 2009. EM\&V standards for feedback programs: quantifying customer behavior. Presented to Behavior, Energy and Climate Change, Washington, DC, November 17.

Loewenstein, G., D. Prelec. 1992. Anomalies in Intertemporal Choice: Evidence and an Interpretation. The Quarterly Journal of Economics. Vol. 107(2): 573-597.

Lutzenhiser, Loren. 1993. "Social and Behavioral Aspects of Energy Use." Annual Review Energy and Environment 18: 247-89.

Martinez, M.S. \& C.R. Geltz. 2005. "Utilizing a pre-attentive technology for modifying customer energy usage." In Proceedings of the ECEEE 2005 Summer Study, 7: 3-11. European Council for Energy Efficient Economy.

McKenzie-Mohr, Doug and William Smith. 1999. Fostering Sustainable Behavior. British Columbia, Canada: New Society Publishers.

McKenzie-Mohr, Doug and William Smith. 2007. Fostering Sustainable Behavior: An Introduction to Community-Based Social Marketing. Gabriola Island, British Columbia: New Society Publishers.

McMakin, Andrea H., Elizabeth L. Malone and Regina Lundgren. 2002. "Motivating Residents to Conserve without Financial Incentives." Environment and Behavior 34(6), 848-863.

Meyer, John [on government isomorphism]

Meyer, John W. 1999. The changing cultural content of the nation-state: a world society perspective. In State/Culture: State-Formation after the Cultural Turn, ed. George Steinmetz. Cornell University Press, Ithaca, NY.

Moezzi, Mithra. 2009. Social sciences for reduced energy use in buildings: past contributions and future potential. Presentation to Integrating Social and Behavioral Insights to DOE Programs and Policies, Washington, DC, October 9. 
Nufrio, Philip M. 2001. Changing Organizational Culture: A Study of National Government. University Press of America, Lanham, MD.

O'Riordan, Timothy, Chester L. Cooper, Andrew Jordan, Steve Rayner, Kenneth R. Richards, Paul Runci and Shira Yoffe. 1998. Institutional frameworks for political action. In Human Choice and Climate Change, Volume 1: The Societal Framework, eds. Steve Rayner and Elizabeth L. Malone. Battelle Press, Columbus, $\mathrm{OH}$.

Owen, Tom, Andrew Pape-Salmon and Brooke McMurchy, 2010. Employee Engagement and Energy Information Software Supporting Carbon Neutrality. Paper submitted to the 2010 ACEEE Summer Study on Energy Efficiency in Buildings.

Pacala, S. and R. Socolow 2004. Solving the climate problem for the Next 50 Years with Current Technologies. Science 305, 968-972.

Pallak, M.S., D.A. Cook, and J.J. Sullivan. 1980. "Commitment and Energy Conservation.” In L. Bickman, ed. Applied Social Psychology Annual (1). Beverly Hills, Calif.: Sage Publications.

Pink, Daniel Drive: The Surprising Truth about What Motivates Us.

Schein, Edgar H. 1999. The Corporate Culture Survival Guide: Sense and Nonsense about Cultural Change. Jossey-Bass, San Francisco.

Schultz P.W., J.M. Nolan, R.B. Cialdini, N.J. Goldstein, and V. Griskevicius. 2007. "The Constructive, Destructive, and Reconstructive Power of Social Norms." Psychological Science. May.

Senge, Peter, Art Kleiner, Charlotte Roberts, Richard Ross, George Roth and Bryan Smith 1999. The Dance of Change: the Challenges of Sustaining Momentum in Learning Organizations. Doubleday, New York.

Smith, Jodi 2005. Obtaining behavior change not just raising awareness. Presented to Australian Association of Environmental Education, SA Division Workshop, Adelaide, 22 June 2005 http://www.emergingself.com.au/About_Jodi-Anne.htm.

Sovacool, Benjamin K. 2009. Rejecting renewables: the socio-technical impediments to renewable electricity in the United States. Energy Policy 37:4500-4513.

Stephenson, Janet, Barry Barton, Gerry Carrington, Daniel Gnoth, Rob Lawson and Paul Thorsnes 2010. Energy cultures: a framework for understanding energy behaviors. Energy Policy $38,6120-6129$.

Stern, Paul. 2009. Designing Effective Policies Using Social Science Insights. Presented to the DOE Energy and Behavior Workshop, October 6, Washington, DC.

Thaler, Richard H. and Cass R. Sunstein 2008. Nudge: Improving Decisions about Health, Wealth, and Happiness. Penguin, New York.

van Nieuw-Amerongen, M. E., S. P. J. Kremers, N. K. de Vries, and G. Kok. 2009. The use of prompts, increased accessibility, visibility, and aesthetics of the stairwell to promote stair use in a university building. Environment \& Behavior, published online October 2. 
Weber, Elke U. and Lindemann, Patricia G. 2007. From intuition to analysis: Making decisions with our head, out heart, or by the book. In Intuition in judgment and decision making, 191-208. Eds. H. Plessner, C. Betsch and T. Betsch. Mahwah, NJ: Lawrence Erlbaum.

Winkler, R.C. and R.A. Winett. 1982. "Behavioral Interventions in Resource Management: A Systems Approach Based on Behavioral Economics.” American Psychologist 37: 421-435.

World Business Council for Sustainable Development 2010. Energy Efficiency in Buildings: Transforming the Market. 